\title{
Analysis and modeling of the seasonal South China Sea temperature cycle using remote sensing
}

\author{
Daniel J. Twigt • Erik D. De Goede • \\ Ernst J. O. Schrama • Herman Gerritsen
}

Received: 21 December 2006 / Accepted: 13 August 2007 / Published online: 12 October 2007

(C) Springer-Verlag 2007

\begin{abstract}
The present paper describes the analysis and modeling of the South China Sea (SCS) temperature cycle on a seasonal scale. It investigates the possibility to model this cycle in a consistent way while not taking into account tidal forcing and associated tidal mixing and exchange. This is motivated by the possibility to significantly increase the model's computational efficiency when neglecting tides. The goal is to develop a flexible and efficient tool for seasonal scenario analysis and to generate transport boundary forcing for local models. Given the significant spatial extent of the SCS basin and the focus on seasonal time scales, synoptic remote sensing is an ideal tool in this analysis. Remote sensing is used to assess the seasonal temperature cycle to identify the relevant driving forces and is a valuable source of input data for modeling. Model simulations are performed using a three-dimensional baroclinic-reduced depth model, driven by monthly mean sea surface anomaly boundary forcing, monthly mean lateral temperature, and salinity forcing obtained from the World Ocean Atlas 2001 climatology, six hourly meteorological forcing from the European Center for Medium range Weather Forecasting ERA-40 dataset, and remotely sensed sea surface temperature (SST) data. A sensitivity analysis of model forcing and
\end{abstract}

Responsible editor: Phil Dyke

D. J. Twigt $(\bowtie) \cdot$ E. D. De Goede $\cdot H$. Gerritsen

WL|Delft Hydraulics,

P.O.Box 177, $2600 \mathrm{MH}$ Delft, The Netherlands

e-mail: daniel.twigt@wldelft.nl

E. J. O. Schrama

Delft University of Technology,

Kluyverweg 1,

2629 HS Delft, The Netherlands coefficients is performed. The model results are quantitatively assessed against climatological temperature profiles using a goodness-of-fit norm. In the deep regions, the model results are in good agreement with this validation data. In the shallow regions, discrepancies are found. To improve the agreement there, we apply a SST nudging method at the free water surface. This considerably improves the model's vertical temperature representation in the shallow regions. Based on the model validation against climatological in situ and SST data, we conclude that the seasonal temperature cycle for the deep SCS basin can be represented to a good degree. For shallow regions, the absence of tidal mixing and exchange has a clear impact on the model's temperature representation. This effect on the large-scale temperature cycle can be compensated to a good degree by SST nudging for diagnostic applications.

Keywords South China Sea - Baroclinic temperature model . Reduced depth modeling $\cdot$ Altimeter data $\cdot$ Radiometer data . Temperature nudging

\section{Introduction}

The goal is to develop and validate a baroclinic temperature model for the South China Sea (SCS). This model should resolve the large-scale seasonal temperature cycle. For reasons of future operational modeling flexibility, we wish to investigate whether this can be achieved when neglecting tides and mesoscale processes. The model is intended for large-scale scenario analysis and for the generation of boundary forcing for local nested models.

To model the seasonal basin-scale temperature cycle of the SCS in a consistent way, it is important to identify the 
processes driving this cycle on these scales. We therefore focus on seasonal transport by residual circulation, on seasonal exchange processes with outside basins and with the atmosphere and on seasonal mixed layer temperature variability. These processes are described in Section 2, which is based on a review of literature in combination with an overview of synoptic water level and temperature data measured by remote-sensing satellites. Our goal is to reproduce these processes, through the model's internal dynamics, and applying the corresponding model seasonally varying forcing. We do not take into account tidal effects on the assumption that the time-integrated effect of tidal mixing and exchange on seasonal transport and stratification is small compared to the large-scale processes governing the seasonal cycle, like the monsoon wind and heat flux systems.

To achieve this, we set up a free-surface baroclinic temperature model that is forced using data from remote sensing, climatological, and meteorological reanalysis datasets. The shared characteristic of these datasets is a good coverage of the SCS at the seasonal and basin-wide scales that are of interest in this study. To model the seasonal exchange at the open-model boundaries, we apply monthly mean water level forcing, obtained from sea surface anomaly (SSA) data and climatological monthly mean lateral temperature and salinity forcing. Momentum and heat flux forcing at the free surface is applied using meteorological reanalysis and remotely sensed surface temperature data. An option exists to blend the latter in our heat flux model using a nudging method applicable for the diagnostic purposes of interest to us. We investigate this option to further improve the quality of the model with respect to temperature in a robust way. Model setup and forcing are discussed in Section 3.

Based on the proposed model setup, we perform a sensitivity analysis. The aim of this analysis is to optimize our model setup and parameterizations and to assess the impact of neglecting tides on the representation of the 3D seasonal temperature cycle. The model performance is quantified based on a goodness-of-fit or least squares norm in the evaluation of results against temperature profiles from climatology. Section 4 describes the sensitivity analysis without sea surface temperature (SST) nudging. To assess the improvement that can be obtained with this option, Section 5 deals with a separate analysis in which SST nudging is applied. The optimized model resulting from our sensitivity analysis is validated in Section 6 by assessing its results against climatological temperature profiles and SST data. We then assess whether the largescale processes identified from literature are resolved by the model and discuss model discrepancies. Conclusions and recommendations are presented in Section 7.

\section{Review of the seasonal South China Sea temperature cycle}

The SCS is the largest sea bordering the Northwest Pacific Ocean, covering a region from the equator to $23^{\circ} \mathrm{N}$ and from 99 to $121^{\circ} \mathrm{E}$. It forms a semienclosed basin with a mean depth of $1,800 \mathrm{~m}$ and a maximum depth of $5,400 \mathrm{~m}$ (see Fig. 1). This basin is enclosed by two continental shelves with depths shallower than 100 m (Wyrtki 1961).

\subsection{Literature review of the SCS seasonal cycle}

After the classical description by Wyrtki (1961), seasonal processes in the SCS are governed to a large extent by the East Asian monsoon system. In this monsoon system, a distinction is made between the North East (NE) or dry monsoon and the South West (SW) or wet monsoon. From October until April, the NE monsoon prevails. This monsoon is fully developed in January, during which a NE wind prevails over the entire basin, often exceeding wind force 5. From May until September, the SW monsoon prevails. This monsoon reaches full development in August when at open sea wind force 4 is often exceeded.

Basin-scale circulation is governed by this monsoon system to a large degree. It can be regarded as barotropic

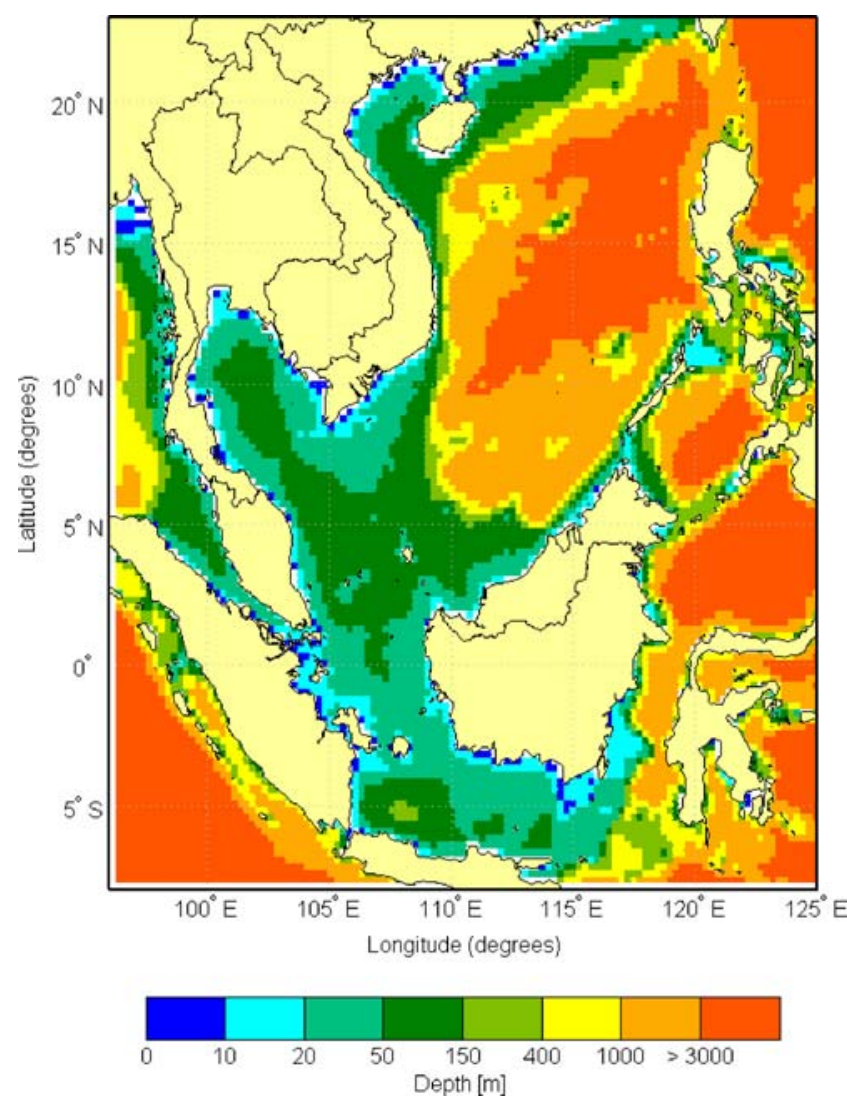

Fig. 1 South China Sea bathymetry. Source: ETOPO2 (NGDC 2006) 
currents because of coastline constraints and wind stress forcing (Wyrtki 1961; Qu et al. 2000). The NE monsoon drives a basin-scale cyclonic circulation both in the northern SCS and in the southern SCS. The SW monsoon drives a weak cyclonic circulation in the north SCS and an anticyclonic circulation in the south SCS (Wang et al. 2003). These large-scale flow dynamics are explained by basin-scale "tilting" of the water levels by wind stress forcing and Coriolis deflection (Liu et al. 2001). During the NE monsoon, this results in strong boundary currents along the Chinese and Vietnamese coastlines (Chu et al. 1998). The basin-scale gyre system results in a west-to-east cross basin current around $16^{\circ} \mathrm{N}$ (Chu et al. 2002; Yang et al. 2002). In the northern SCS, large-scale seasonal Rossby waves are reported to play a role in the formation of the seasonal gyre system (Yang and Liu 2003).

Exchange with other systems mainly occurs through Luzon Strait (Jilan 2004). The Kuroshio current of the Pacific Ocean enters the SCS through this strait by means a so-called loop current (Centurioni et al. 2004). At critical wind stress levels, the current deflects into the SCS, and influx occurs. This mainly happens during the $\mathrm{NE}$ monsoon, and can be explained by higher wind speeds and a preferable wind direction (Farris and Wimbush 1996). On the northern shelf, exchanges with the East China Sea occur through Taiwan Strait (Wang et al. 2004).

The surface layer temperature in the SCS has a strong seasonal signal, related to the monsoon system. During the NE monsoon, increased wind stress causes entrainment of colder and denser water into the mixed layer, resulting in a deeper mixed layer and a lower temperature. During the SW monsoon, wind stress decreases, and heat gained from the atmosphere is trapped in the shallower mixed layer, causing a rise in surface layer temperature ( $\mathrm{Qu}$ 2001). The surface heat flux, which reaches peak values during the onset of the SW monsoon and low values during the NE monsoon, plays an important role in this cycle (Chou et al. 2001). During the NE monsoon, transport along the Chinese and Vietnamese coastlines by boundary currents has a significant impact on temperature. During the NE monsoon, these processes amount to the formation of a frontal thermal structure in the northern SCS (Wang et al. 2001). A strong coastal front forms along the Chinese coastline and a relatively weak and wide front forms across the SCS basin around $16^{\circ} \mathrm{N}$ (Chu et al. 2002). The cumulative effect of these processes results in a seasonal temperature amplitude of more than $6^{\circ} \mathrm{C}$ in the northern SCS and between 2.5 and $4^{\circ} \mathrm{C}$ in the southern SCS (Chu et al. 1997).

The mixed layer depth varies seasonally and is always above $120 \mathrm{~m}$ in the deep SCS basin. In this region, stratification is observed continuously throughout the year. In the shallow regions over the continental shelves, changing wind effects will break down stratification on a seasonal basis $(\mathrm{Qu}$ 2001). Seasonal temperature variability mainly occurs in the upper layers. Below $300 \mathrm{~m}$ depth, no seasonal variability is observed (Chu et al. 2002).

\subsection{Data review of the SCS seasonal cycle}

The seasonal circulation and temperature cycles are extracted from the water level and temperature data measured by remote-sensing satellites. SSA and absolute dynamic topography (ADT) data have been obtained from the Developing Use of Altimetry for Climate Studies (DUACS) altimetry database (DUACS 2004, 2005). Of these dynamic topographies, SSA provides a measure for dynamic variability relative to the mean component of the flow. The ADT includes this mean component or permanent current pattern as well. SST data has been obtained from the advanced veryhigh-resolution radiometer (AVHRR)/Pathfinder dataset (Vazquez 2004). Multiple years of data are assembled into monthly-mean climatologies to study seasonally reoccurring features. January and August fields of SSA, ADT, and SST, corresponding with the NE and SW monsoon highs, are shown in Figs. 2, 3 and 4, respectively. In the ADT fields, a qualitative assessment of the large-scale flow is included based on geostrophic circulation. Both the SSA and ADT data have been corrected for tides and as such provide a measure for residual circulation by nontidal processes.

From Fig. 2, an inversion in SSA patterns is observed between January (NE monsoon) and August (SW monsoon). This inversion is explained by water level tilting forced by the monsoon wind and pressure system, confirming the leading role of the monsoon on seasonal basin-scale circulation (see, for instance, Liu et al. 2001).

These monsoon-driven currents attribute to a cyclonic circulation during the NE monsoon and a combined cyclonic/anticyclonic circulation during the SW monsoon (Fig. 3). This confirms the basin-scale gyre system described by Wang et al. (2003). It also confirms the relation between this gyre system and the monsoon by the relation with the seasonal SSA fields in Fig. 2. The seasonal cross-basin current around $16^{\circ} \mathrm{N}$ described by Chu et al. (2002) and the boundary currents along the Chinese and Vietnamese coastlines described by Chu et al. (1997) are explained on the basis of this gyre system.

A bifrontal temperature structure is observed during the NE monsoon, which diminishes during the SW monsoon (Fig. 4). A first front runs between Luzon and Vietnam, glancing off the Vietnamese coastline (front 1). A second front follows the Chinese coastline, originating from the East China Sea (front 2). This is similar to the frontal temperature system described in literature by $\mathrm{Chu}$ et al. (2002). Comparing it with Fig. 3, we observe that the 

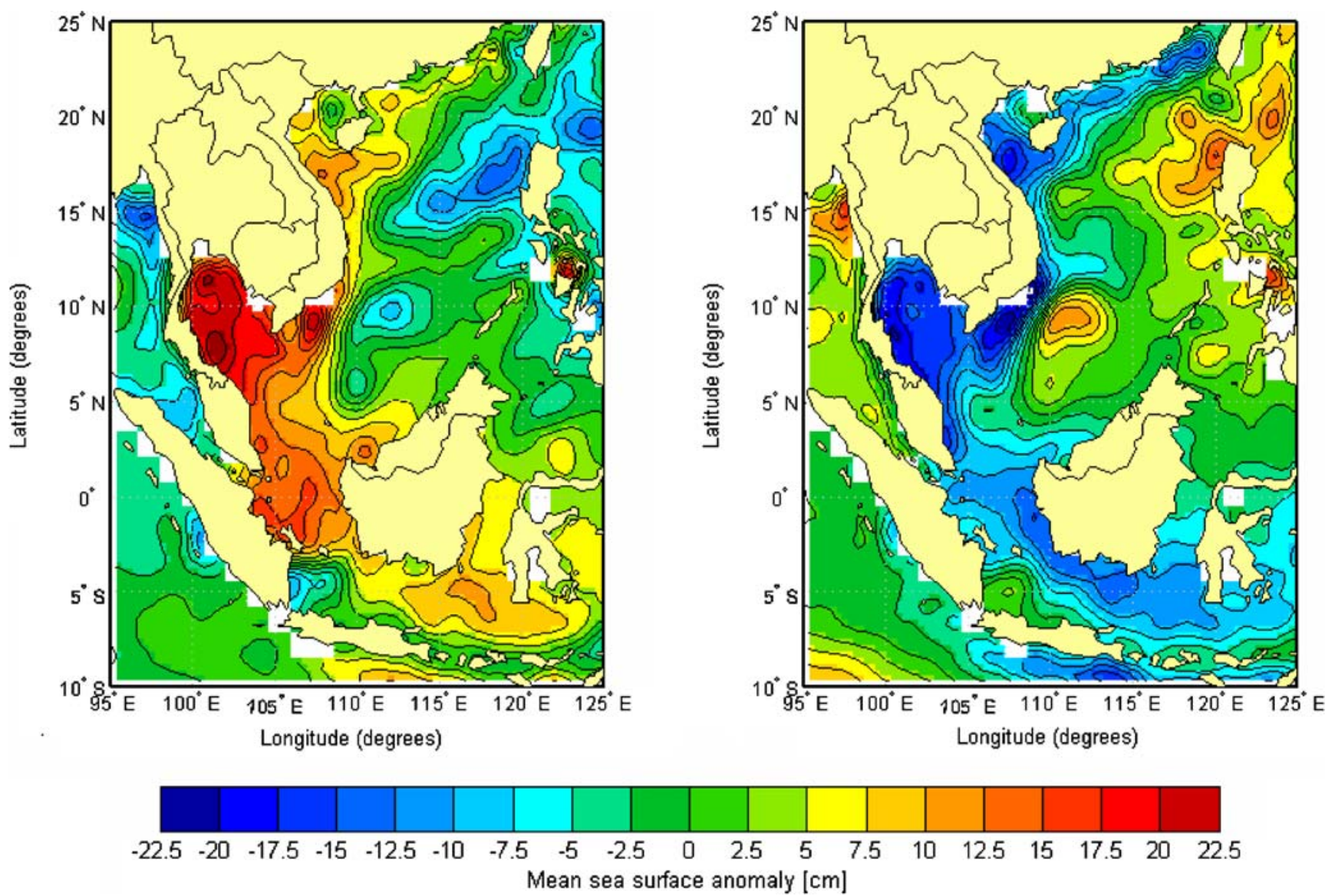

Fig. 2 Climatological, monthly-mean sea surface anomaly (SSA) fields for January (left) and August (right). Assembled from 1992 to 2001 DUACS SSA data (DUACS 2005). Height with respect to CLS01 reference surface (Hernandez et al. 2001)

frontal patterns are similar in shape as the circulation patterns, indicating that they are driven by the same physical phenomenon, which is the monsoon forcing.

Figure 5 shows the time and area averaged heat flux over the SCS basin. Peak values occur during the intermediate periods between the monsoons. During the monsoon periods, the net heat flux can be negative, indicating that the water temperature will drop because of heat exchange at the free surface. This is in analogy with the monsoon-related net heat flux cycle described in literature by Qu (2001).

Both literature and data confirm that the observed largescale temperature features on seasonal timescales are related to the monsoon wind and heat flux cycles. Moreover, the monsoon system plays a leading role in the buildup of these features by its effect on seasonal transport by the residual circulation, seasonal heat flux variations, and seasonal exchange with other basins. This justifies our hypothesis that it should be possible to model the seasonal temperature cycle by focusing on these processes rather than on smallscale effects of tidal mixing and exchange. In Section 6, we will revisit the hypothesis and assess whether the relevant processes are adequately resolved by the model.

\section{The baroclinic temperature model}

The starting point of the study is an existing free-surface hydrodynamic model application for the area of interest. It is based on a barotropic depth-integrated time-stepping model with a variable Coriolis parameter on a $1 / 4 \times 1 / 4^{\circ}$ spherical, staggered Arakawa C-grid, advancing with a time step of $5 \mathrm{~min}$. This application was developed for SCS tidal and seasonal flow modeling applications (Gerritsen et al. 2003, 2004). Because our focus is on seasonal temperature processes, the model is adapted to represent baroclinic flow by including salinity and temperature as transport parameters. Because temperature variability is mainly a threedimensional process in the upper layers of the ocean, the model is applied in 3D mode ( $\sigma$-layer approach) and with depth truncated at below the annual maximum thermocline depth. As our focus is on nontidal processes at seasonal scales anyway, this allows for a significantly larger time step given the Courant-Friedrichs-Lewy stability constraints of the model. This is described in more detail in Sections 3.2 and 3.3 below. The model simulations have been carried out with the DELFT3D generic shallow water 

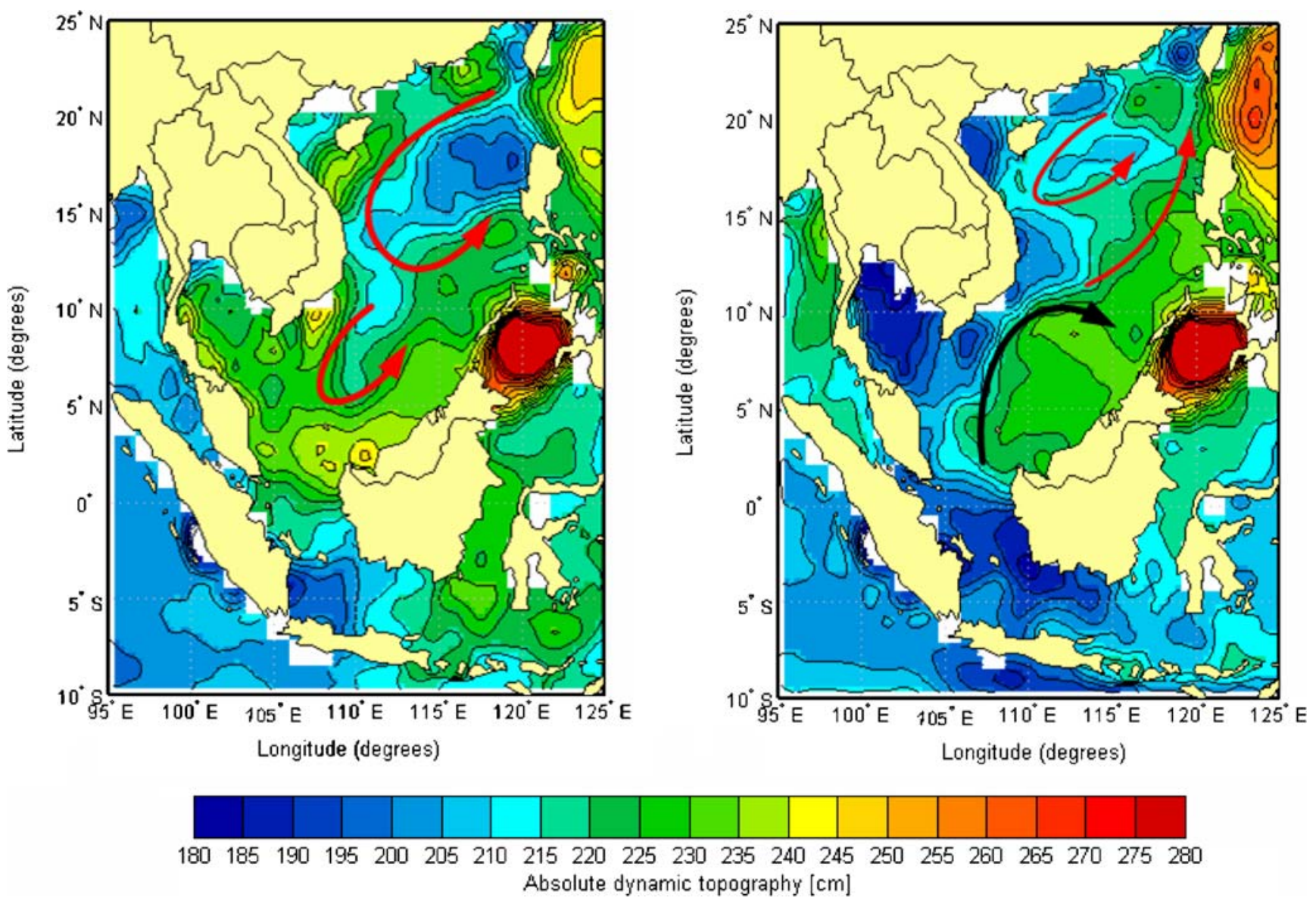

Fig. 3 Climatological, monthly mean absolute dynamic topography (ADT) fields for January (left) and August (right). Assembled from 2002 to 2004 DUACS ADT data (DUACS 2004). The arrows indicate large-scale geostrophic circulation patterns. Red indicates cyclonic circulation, and black indicates anticyclonic circulation. Height with respect to EIGEN2 geoid surface (Rio and Hernandez 2003)
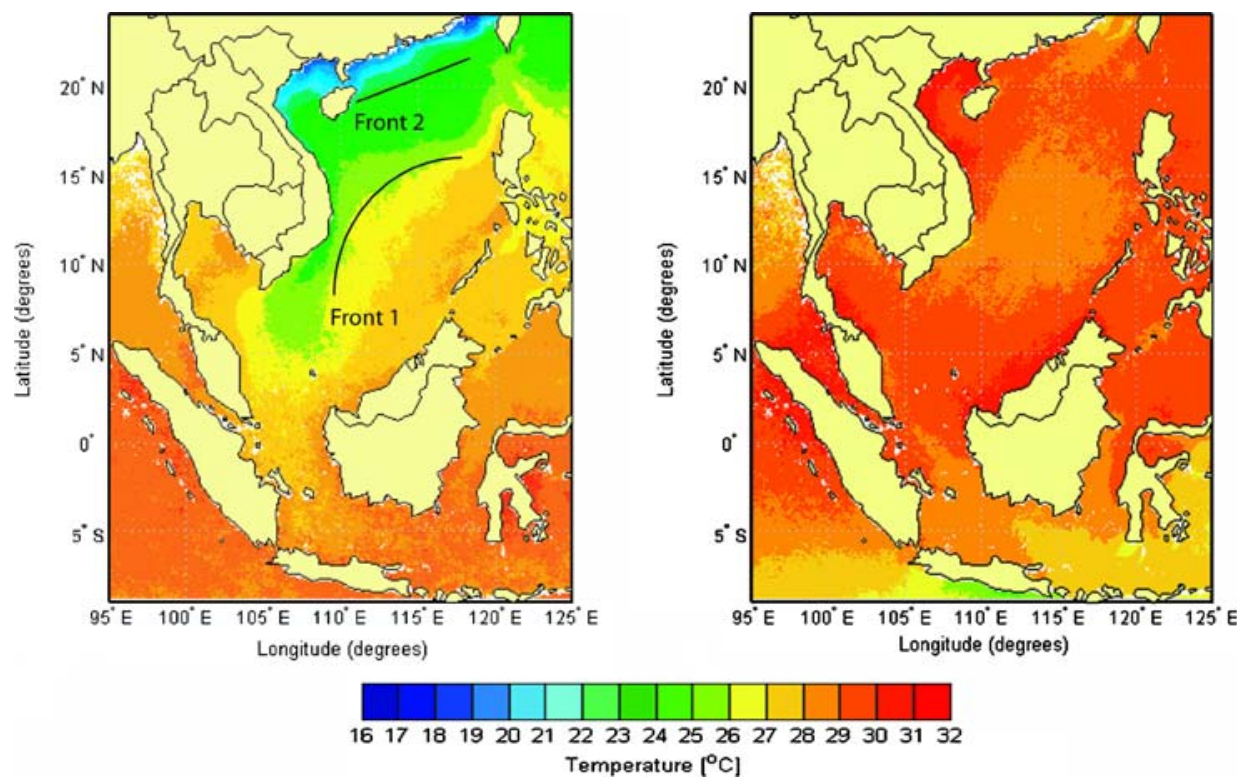

Fig. 4 Climatological, monthly mean sea surface temperature (SST) for January (left) and August (right). Assembled from 1994 to 2004 AVHRR/Pathfinder SST data (Vazquez 2004) 
Fig. 5 Climatological, monthly mean surface heat flux components: short wave, long wave, convective, evaporative, and net heat flux. Assembled from 1983 to 2002 ECMWF ERA-40 data (Kallberg et al. 2004) spatially averaged over $100-120^{\circ} \mathrm{E}, 5^{\circ} \mathrm{S}-25^{\circ} \mathrm{N}$. Signs indicate whether the component is incoming $(+$ sign $)$ of outgoing (-sign)

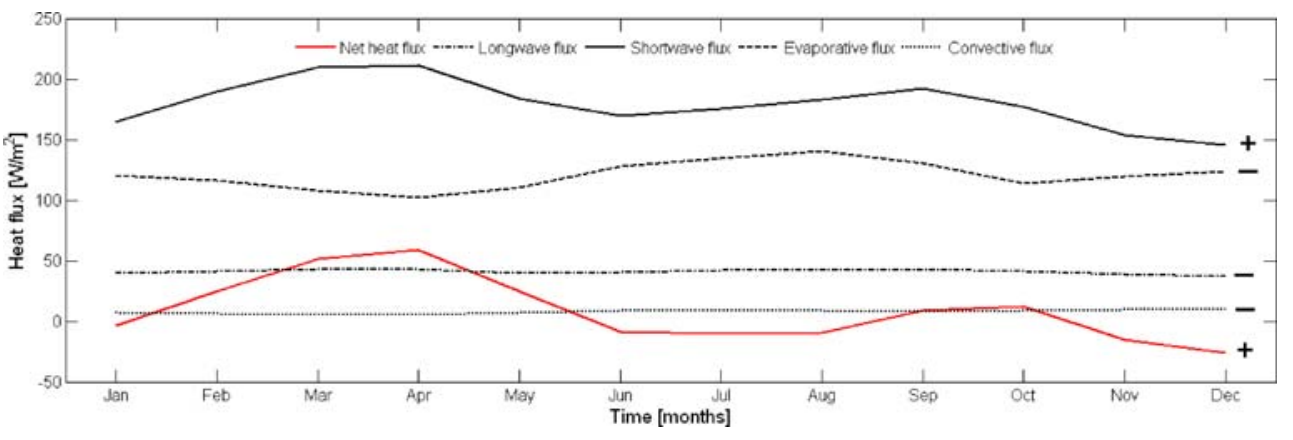

modeling system, described in detail in Lesser et al. (2004) and in Kernkamp et al. (2005).

\subsection{Model area and open boundary forcing}

Figure 6 shows the spatial extent and open boundaries of the model domain. We note that the model grid covers a larger spatial extent than the deep SCS. For the interpretation of results, we will focus on the SCS, although. At the open model boundaries (blue lines in Fig. 6), water level forcing is imposed based on monthly mean climatological SSA data from DUACS (2004). We choose to force the model using these relative water levels and neglect the difference in mean water level between the model open

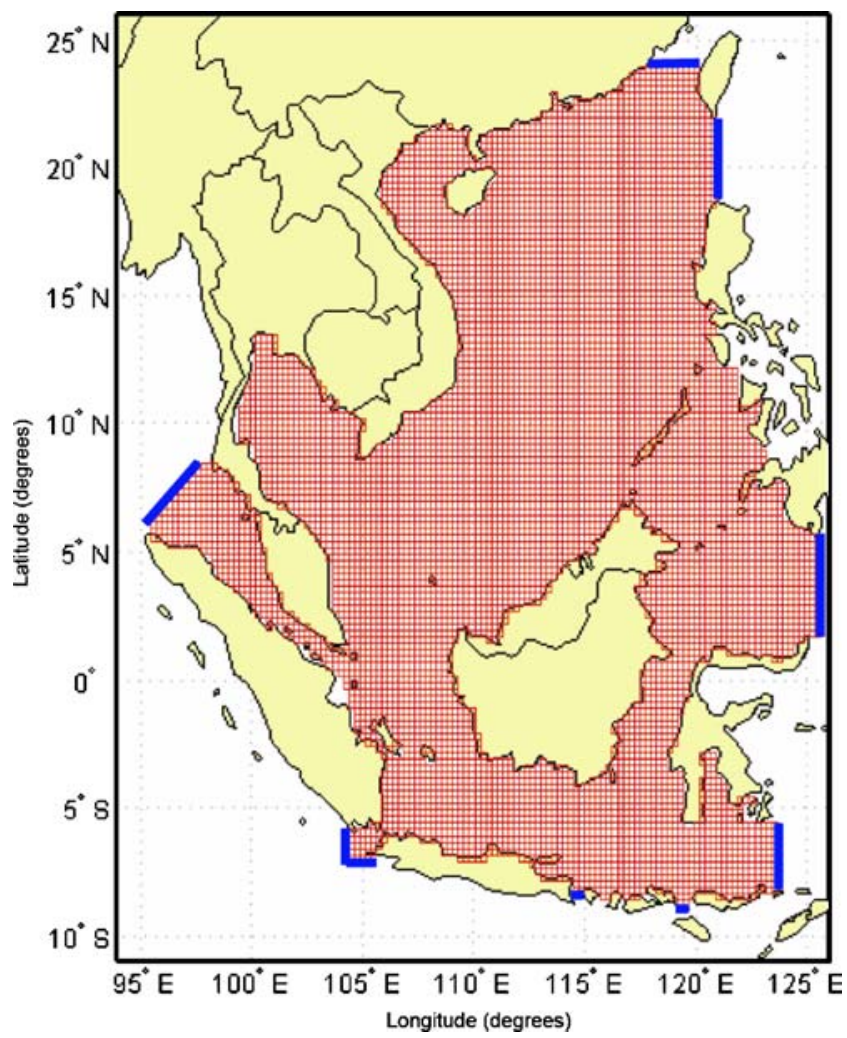

Fig. 6 Model grid and open boundaries of the $1 / 4 \times 1 / 4^{\circ}$ spherical South China Sea model application. Blue lines indicate the lateral open model boundaries boundaries, as this difference is small (below $5 \mathrm{~cm}$ ) and not accurately known. The seasonal variations in the SSA water levels are larger $(20 \mathrm{~cm}$ on average) and have a better accuracy. Because our primary interest is in seasonal variations, we thus choose to neglect the mean component, which also provides consistency with the SSA data we use for model validation (see Section 6).

Lateral temperature and salinity forcing is imposed at the open boundaries using monthly mean climatological data from the World Ocean Atlas 2001 (Levitus 1982; Boyer et al. 2005).

The forcing data at the open boundaries represents the seasonal exchange processes with the nonmodeled part of the world ocean, while not imposing shorter time-scale variations such as tides.

\subsection{Model bathymetry}

The significant depth of the SCS basin $(>5,000 \mathrm{~m}$.) negatively affects the time step in the numerical model. We therefore apply a reduced depth approach (Gerritsen et al. 2004). As a result of this truncation, the propagation of barotropic processes like tides is distorted. As we focus on much slower propagating seasonal processes and do not take into account the barotropic tidal forcing, the present modeling does not suffer from this. Below the mixed layer depth, the transport is small. By truncating the model below this point, unresolved energy exchange to deeper levels is assumed to be negligible. Based on assessments of mixed layer depth and vertical temperature variability described in Qu (2001) and Chu et al. (2002), the model is truncated at $300 \mathrm{~m}$ depth. We acknowledge that by truncation at 300 meters depth, deep-reaching upwelling at the continental shelf break and by large-scale eddies is not taken into account but assume these processes are of second order with regard to the main driving forces of the seasonal temperature cycle.

A vertical $\sigma$-layer scheme is applied with 20 uniformly distributed layers, resulting in a vertical resolution of $15 \mathrm{~m}$ over the truncated part of the basin, smoothly decreasing toward the ocean margins and the coast. Based on mixed layer dynamics such as described in literature (Qu 2001), 
it is assumed that this resolution is sufficient to capture the large-scale mixed layer dynamics.

\subsection{Model time step}

Based on stability requirements for the truncated depth, a time step of $2 \mathrm{~h}$ is applied, which allows for a good sampling of the seasonal processes of interest. Model simulations are made for a climatological year, applying a 1 year spin-up from initial temperature and salinity conditions determined from the World Ocean Atlas 2001. Model runtimes are approximately $3 \mathrm{~h}$ on a $3-\mathrm{GHz}$ Pentium 4 personal computer for a 1-year simulation, which will provide adequate flexibility in future scenario analysis.

\subsection{Free surface heat flux and momentum forcing}

For the heat exchange at the free surface, a heat flux model is used, which takes into account the separate effects of shortwave and net longwave radiation and heat exchange because of evaporation and convection (De Goede et al. 2000). The resulting heat flux ( $Q_{\text {tot }}$ in Eq. 1 ) is included in the temperature transport equation (Eq. 2) as a source term in the upper layer:

$Q_{\mathrm{tot}}=Q_{\mathrm{sn}}-Q_{\mathrm{ebr}}-Q_{\mathrm{ev}}\left(c_{\mathrm{d}}\right)-Q_{\mathrm{co}}\left(c_{\mathrm{s}}\right)$

$\frac{\partial T_{s}}{\partial t}=$ advection + diffusion $+\frac{Q_{t o t}}{\rho_{o} c_{p} \Delta z_{s}}$

where $Q_{\mathrm{sn}}$ represents the net solar radiation, $Q_{\mathrm{ebr}}$ represents the effective back radiation, $Q_{\mathrm{ev}}$ represents the heat exchange by evaporation, and $Q_{\text {co }}$ represents the heat exchange by convection. While $Q_{\mathrm{sn}}$ and $Q_{\mathrm{ebr}}$ are based on theoretical relations, $Q_{\mathrm{ev}}$ and $Q_{\mathrm{co}}$ are based on empirical bulk formulations and are scalable by the transfer coefficients $c_{\mathrm{d}}$ (Dalton number) and $c_{\mathrm{s}}$ (Stanton number) (Twigt 2006). The heat flux is prescribed at the upper model layer, the depth of which is indicated by $\Delta z_{\mathrm{s}}$. This heat model has relatively few free parameters and is preferred for its subsequent robustness. In Section 5, Eq. 2 will be extended with an additional term to nudge the modeled surface temperature toward remotely sensed surface temperature data.

Vertical turbulent mixing is computed by a $k-\varepsilon$ closure model, while in the horizontal direction, constant eddy viscosity and eddy diffusivity values are applied. The process of turbulent mixing through the thermocline by internal waves is modeled using the Ozmidov length-scale concept. We will optimize the Ozmidov length-scale parameter in a model sensitivity analysis to further improve the model's temperature representation.

At the free surface, the effect of wind stress is taken into account via the Smith and Banke (1975) formulation. At the sea bed, the bed stress is defined based on a Manning formulation with a constant Manning coefficient of 0.026 . Both wind and bed stresses are prescribed as boundary conditions in the momentum equations and the $k-\varepsilon$ turbulence model.

Surface forcing data consist of space- and time-varying air temperature, relative humidity, cloud coverage, wind, and pressure. These are obtained from the European Center for Medium range Weather Forecasting (ECMWF) ERA-40 dataset, which has a $2.5 \times 2.5^{\circ}$ spatial resolution and a maximum temporal resolution of $6 \mathrm{~h}$. Space- and timevarying ECMWF wind and pressure data at the same resolution is applied for momentum forcing at the free surface. Based on the characteristic scales of this forcing data, seasonal and basin-scale monsoon and shorter-scale atmospheric forcing are imposed on the model.

\section{Model sensitivity analysis}

A sensitivity analysis of the model forcing data and the model coefficients is performed. The goal of this analysis is to study the sensitivity of the modeled seasonal temperature to variation of these quantities. Furthermore, the model's sensitivity to user defined coefficients affecting mixing processes (horizontal diffusivity, Ozmidov length scale) is studied to assess the impact of unresolved tidal mixing.

\subsection{Model accuracy assessment}

Model results are analyzed in a quantitative and objective way by minimizing a cost function or goodness-of-fit norm, using monthly mean validation data from the World Ocean Atlas 2001 (WOA; Levitus 1982). Monthly mean $(t)$ model data (Model) at each horizontal grid point $(n, m)$ and model layer $(\sigma)$ is compared with this data by evaluating the cost function:

$\mathrm{GoF}=\frac{\sum_{\mathrm{n}, \mathrm{m}} \sum_{\mathrm{t}} \sum_{\sigma}\left\{W_{t, \sigma, n, m} \times\left|\operatorname{Model}_{t, \sigma, n, m}-W O A_{t, \sigma, n, m}\right|\right\}}{\sum_{\mathrm{n}, \mathrm{m}} \sum_{\mathrm{t}} \sum_{\sigma}\left\{W_{t, \sigma, n, m}\right\}}$

with $W_{t, \sigma, n, m}$ as a weight function. The resulting GoF is presented as either a spatially varying field of time and layer averaged values, allowing the assessment of spatial variations in model performance, or as a domain-averaged single value, which reflects the overall model quality. We apply a uniform value of 1 for the weight function $W_{t, \sigma, n, m}$.

\subsection{Model sensitivity analysis}

We will assess the model sensitivity to some parameters and forcing compared to a reference model setup in which 
monthly mean data is applied for all model forcing (see Section 3). In the reference setup, the heat flux model uses coefficient values $c_{\mathrm{d}}=0.0015, c_{\mathrm{s}}=0.0009$, based on (Smith et al. 1996). A wind-drag coefficient of $c_{\mathrm{d}}=8.3 \times 10^{-4}$ is applied. The horizontal eddy diffusivity equals $1 \mathrm{~m}^{2} / \mathrm{s}$. Based on this reference setup, a number of successive sensitivity runs have been carried out, which are summarized in Table 1.

The adaptations for these runs are made in a consecutive way to iteratively improve the model. With respect to the reference setup outlined above, the heat flux models transfer coefficients are optimized in Run 2 . The sensitivity to changes in vertical mixing is studied in Run 3 and to horizontal mixing in Run 4. The sensitivity to variation of the meteorological forcing, which affects both the heat flux and mixing, is studied in Run 5. Additional variants of wind-induced mixing are considered in Run 6 . The spatially varying GoF fields for these six runs are shown in Fig. 7. We note that at this point, the free surface heat flux is determined based on the heat flux model only, without any SST nudging.

It is observed that the reference setup (Run 1) results in a significant misfit with respect to the validation data. This is a consequence of excessive model heating, mainly during the onset of the SW monsoon when the net heat flux is largest. By increasing the evaporative $\left(c_{\mathrm{d}}\right)$ and convective $\left(c_{\mathrm{s}}\right)$ transfer coefficients of the heat flux model, heat loss as a result of evaporation and convection increases, decreasing the net influx. This results in a better model representation and a smaller misfit over the entire model domain, shown by Run 2. Based on a number of sensitivity experiments, involving optimization with a small-scale test model and comparison with the heat exchange observed from climatological data, transfer coefficients $c_{\mathrm{d}}$ and $c_{\mathrm{S}}$ were both found to have optimum values near 0.0021 (Twigt 2006).

Table 1 Definition of model runs and mean difference or misfit with respect to World Ocean Atlas validation data (Levitus 1982; Boyer et al. 2005)

\begin{tabular}{lll}
\hline Run & Definition & GoF $\left[{ }^{\circ} \mathrm{C}\right]$ \\
\hline 1 & Reference setup & 5.09 \\
2 & Run $1+$ higher transfer coefficients: & 2.41 \\
& $\quad c_{\mathrm{d}}=0.0021, c_{\mathrm{s}}=0.0021$ & \\
3 & Run $2+$ Ozmidov length scale & 2.34 \\
& of $0.07 \mathrm{~m}$ \\
4 & Run $3+$ horizontal diffusivity increased & 2.32 \\
& to $250 \mathrm{~m}^{2} / \mathrm{s}$ \\
5 & Run $4+6 \mathrm{~h}$ temporal resolution \\
& meteorological forcing & 1.99 \\
6 & Run $5+$ increased wind drag & 1.76 \\
& fcoefficient to $C_{\mathrm{d}}=2 \times 10^{-3}$ & \\
\hline
\end{tabular}

This might also indicate that their magnitude as given in Smith et al. (1996), which was determined for high-latitude regions and is widely used in literature, is too low for equatorial and tropical regions. It was found that the impact of increasing the evaporative transfer coefficient is an order of magnitude larger than that of increasing the convective transfer coefficient. This is understood from the larger magnitude of the evaporative heat flux over the SCS basin ( $\pm 120 \mathrm{~W} / \mathrm{m}^{2}$ vs $\pm 10 \mathrm{~W} / \mathrm{m}^{2}$, see Fig. 5).

To assess the model's sensitivity to changes in the modeled vertical mixing, the Ozmidov length scale is increased from 0 to $7 \mathrm{~cm}$ in Run 3. In this way, the time-integrated effect of mixing by internal waves is taken into account. The coefficient was found to have an optimum value at $7 \mathrm{~cm}$ based on sensitivity experiments with our model (Twigt 2006). It is concluded that this increases the overall model representation by a small degree, with the most significant effect observed in the shallow model regions. In the northern SCS, this improvement may be explained by the significant effect of internal waves on vertical mixing (Lynch et al. 2004). In the shallow regions, internal waves are observed less frequently, which may indicate that in these regions, the increased Ozmidov length scale is compensating for missing tidal turbulence. In these shallow regions, it is likely that turbulent mixing by the tides and its effect on the seasonal stratification cannot be neglected.

The model's sensitivity to horizontal mixing is assessed in Run 4 by increasing the horizontal diffusivity from 1 to $250 \mathrm{~m}^{2} / \mathrm{s}$. This leads to a small improvement in model temperature representation along the shelf-edge, indicating that turbulent mixing is underestimated in these regions by the low initial horizontal diffusivity value. We note, however, that a part of the misfit in these regions may be explained by coarse-model resolution along the shelf break, preventing an adequate representation of subsurface upwelling.

The model's sensitivity to changes in meteorological forcing data is assessed in Run 5. The temporal resolution of this forcing data is increased from 1 month to $6 \mathrm{~h}$. This affects both the momentum transfer at the free surface by wind and atmospheric pressure and the net surface heat flux calculated by the heat flux model. This leads to a significant improvement in model temperature representation, notably along the northern Vietnamese coast and in the Gulf of Thailand and the western Java Sea (Fig. 7). This result implies that our initial assumption of meteorological forcing at longer time scales for seasonal modeling purposes does not hold. We explain this by the fact that when using forcing data at a $6 \mathrm{~h}$ resolution, smaller-scale processes like the day-night heat flux cycle and storm surges attributing to stronger mixing are resolved to a reasonable degree. However, if monthly mean forcing data are applied, these processes are smoothed and underestimated by the averaging of the data. This temporally 
Run 1

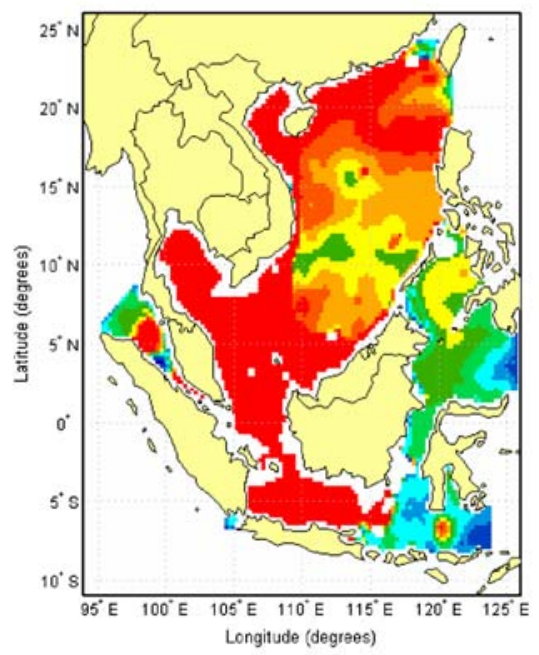

Run 4

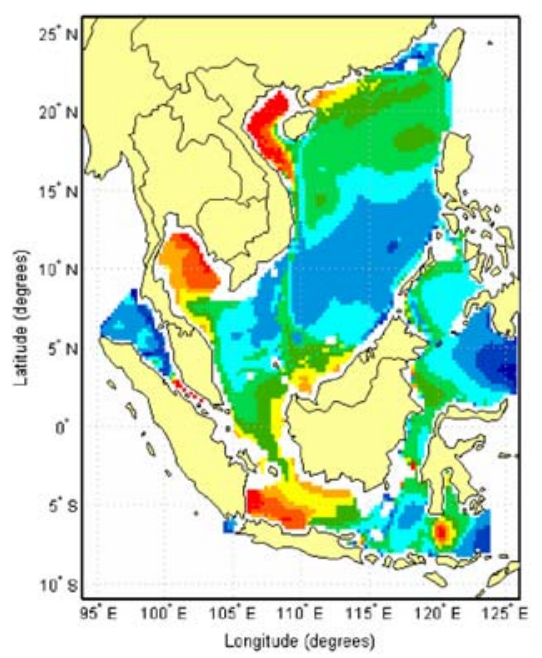

Run 2

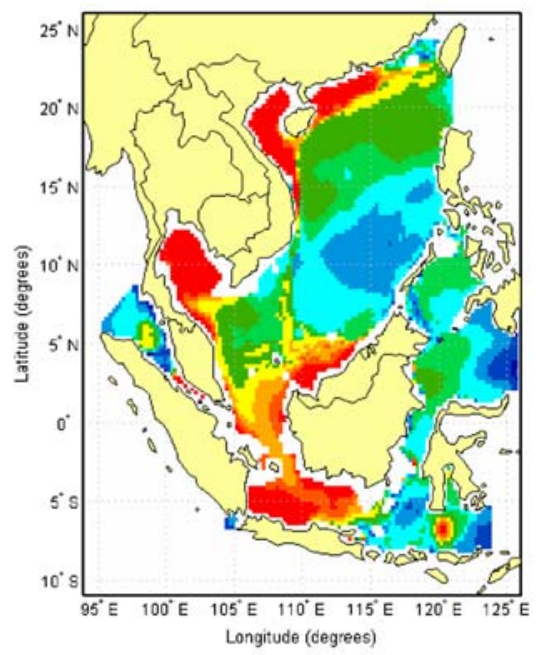

Run 5

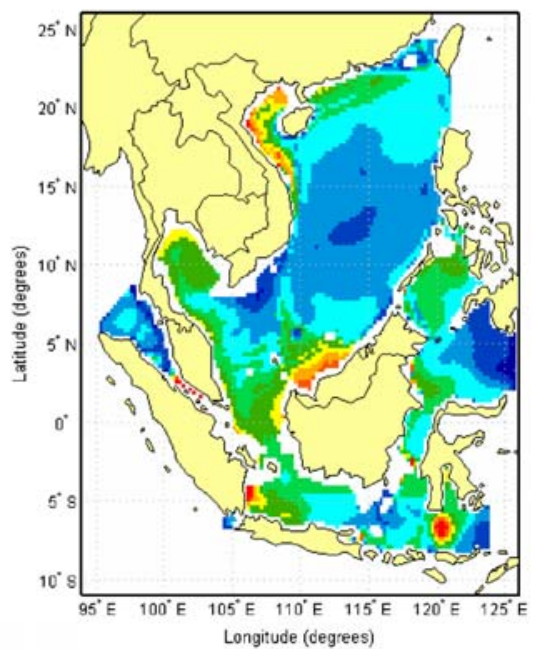

Run 3

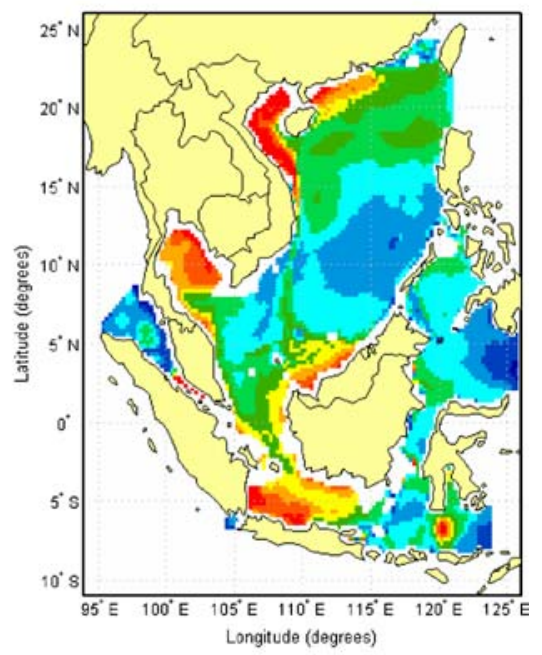

Run 6

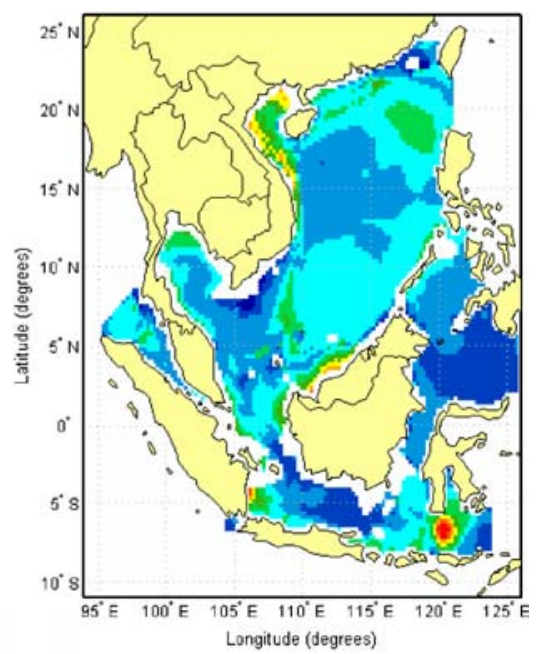

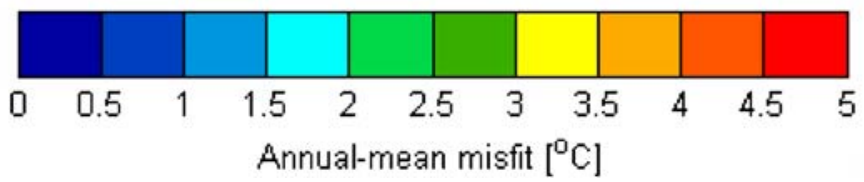

Fig. 7 Time and layer average misfit between model results with respect to World Ocean Atlas 2001 validation data (Levitus 1982; Boyer et al. 2005). See Table 1 for run definitions. No SST nudging is applied

high-resolution data lead to a better representation of entrainment and detrainment of water into the mixed layer by the monsoon winds and subsequent mixed layer temperature variations.

An additional analysis of the model's sensitivity to changes in wind forcing is made in Run 6 . The wind drag coefficient is increased from $C_{\mathrm{d}}=8.3 \times 10^{-4}$ to $C_{\mathrm{d}}=2 \times 10^{-3}$. This value is suggested in Open University (1989), whereas the value used in the previous setup was applied in Gerritsen et al. (2004). This increase by a factor 2.4 has a significant effect on the model temperature representation in the shallow regions, indicating that mixing and exchange processes in these regions are unresolved or underestimated by the model as a consequence of neglecting the tides. In this case, the absence of this process is compensated by increased wind-induced mixing. In the deep model regions, the solution deteriorates for an increased wind drag coefficient, indicating that in these regions, mixing effects are now overestimated. Although the overall model performance has improved compared to Run 5 by increasing the wind drag coefficient, we nevertheless choose to use Run 5 as a starting point for the data assimilation runs, 
because our main area of interest is the central SCS where a better solution is obtained for that run. The data assimilation is described in Section 6.

Based on the sensitivity analysis in this section, we achieve a mean time and basin volume averaged misfit of $1.99^{\circ} \mathrm{C}$ with respect to the World Ocean Atlas 2001 validation data. While this result is already reasonable with respect to the complex interplay of processes attributing to the seasonal cycle, we will try to further improve it using a SST nudging technique.

\section{Data assimilation by sea surface temperature nudging}

The previous section showed that when using the model setup described in Section 3, a considerable error in modeled temperature exists over the shallow model regions. This error was shown to be the result of neglecting tidal mixing and exchange.

To further increase the models temperature representation in regions where the error is still large, we assimilate remotely sensed surface temperature data using a nudging method. This implies that observational and model data are blended by adding a Newtonian relaxation term to the model equations. This method is robust and computationally efficient when compared to other more sophisticated methods of data assimilation (Fu and Cazenave 2001). We note, however, that this method also implies that we fit our model results to observations. As this fitting is not based on the physics of the system, this might lead to inconsistency with respect to the actual forcing mechanisms. Therefore, we will also consider a model without nudging applied during our model validation in Section 6.

We implement the nudging method by adding a correction term to the heat flux model (Eq. 2), which can be written as:

$$
\frac{\partial T_{s}}{\partial t}=\text { advection }+ \text { diffusion }+\frac{Q_{t o t}}{\underbrace{\rho_{o} c_{p} \Delta z_{s}}_{\text {original formulation }}}+\alpha \frac{\frac{\partial Q}{\partial T}\left(T_{S S T}-T_{s}\right)}{\underbrace{\rho_{o} c_{p} \Delta z_{s}}_{\text {correction term }}}
$$

The new correction term is based on a first-order Taylor series expansion around the SST $T_{\mathrm{SST}}$, with $\partial Q / \partial T$ the derivative of Eq. 1 with respect to water temperature $T_{\mathrm{s}}$. The nudging coefficient $\alpha$ is included to prescribe the relative importance of the correction term with respect to the original formulation. This implies that for a low value of $\alpha$, the surface heat flux is based on the solution of the heat flux model mainly, whereas for a high value emphasis is placed on observational values. $T_{\mathrm{SST}}$ represents the observed surface temperature. This approach means that we assimilate the measured skin temperature into the models surface layer. Vertical temperature variability is determined based on the model dynamics.

We use weekly Reynolds SST data in the nudging term. This data consists of preprocessed AVHRR data, interpolated to a fixed grid (Reynolds et al. 2002). We note that this dataset is different from the World Ocean Atlas 2001 data that we use for validation purposes.

Starting with the improved model setup from our sensitivity analysis described in Section 4, the impact of this method with regard to modeling the seasonal temperature cycle is assessed. In Section 5.1, this is first done by comparing time series of modeled and in situ temperature for varying values of $\alpha$. Next, a validation on the basis of the goodness-of-fit norm and World Ocean Atlas 2001 validation data described in Section 4.1 is conducted.

\subsection{Model sensitivity to SST nudging}

The model results for varying values of nudging coefficient $\alpha$ (see Eq. 4) at a station in the deep northern SCS $\left(22^{\circ} \mathrm{N}\right.$, $\left.117^{\circ} \mathrm{E}\right)$ and one in the shallow southern regions $\left(5^{\circ} \mathrm{N}, 116^{\circ} \mathrm{E}\right)$ are shown in Fig. 8. Based on a comparison with climatological data from the World Ocean Atlas 2001, it is concluded that the model setup as optimized in Section 4 provides an adequate representation of temperature in the deep regions. Changes in model results for an increase in $\alpha$ are minimal. In the shallow southern regions, we observe a significant increase in model accuracy for an increasing value of $\alpha$. This means that by nudging the model, results show hardly any improvement in the deep regions, while they significantly improve in the shallow regions.

Obtained GoF results are shown in Fig. 9 and Table 2, where they are presented as monthly mean time and layer averaged misfits or differences with the World Ocean Atlas 2001 validation data. We note that Run 5 as described in Section 4 is used as a reference for this analysis, as this run provided the lowest difference in the deep central SCS without application of nudging.

It is concluded that the model misfit significantly decreases when surface temperature nudging is applied. The effect is most significant in the shallow model regions on the continental shelves. In Section 4, the initial model misfit in these regions is explained by insufficient mixing as a consequence of neglecting tides. The nudging approach compensates for this by forcing the model toward the observed temperature state, albeit that it does not represent the actual forcing mechanism.

In the deep model regions, the effect of temperature nudging is small. This confirms observations in Section 4 that the model temperature representation without nudging is already reasonable in the deep model regions.

A considerable misfit persists along the shelf-edge, which is attributed to unresolved upwelling of subsurface 
Fig. 8 Time series of modeled and World Ocean Atlas 2001 (Levitus 1982; Boyer et al. 2005) surface layer temperature at model test stations in the deep, northern South China Sea $\left(22^{\circ} \mathrm{N} 117^{\circ} \mathrm{E}\right.$, upper panel $)$ and the shallow, southern South China Sea $\left(5^{\circ} \mathrm{N} 116^{\circ} \mathrm{E}\right.$, lower panel). Model results are for an increasing nudging coefficient $\alpha$. The range included with the World Ocean Atlas 2001 data indicates the standard deviation from the climatological mean. SST nudging is applied
Northern $\operatorname{SCS}\left(22^{\circ} \mathrm{N}, 117^{\circ} \mathrm{E}\right)$ surface layer temperature time-series

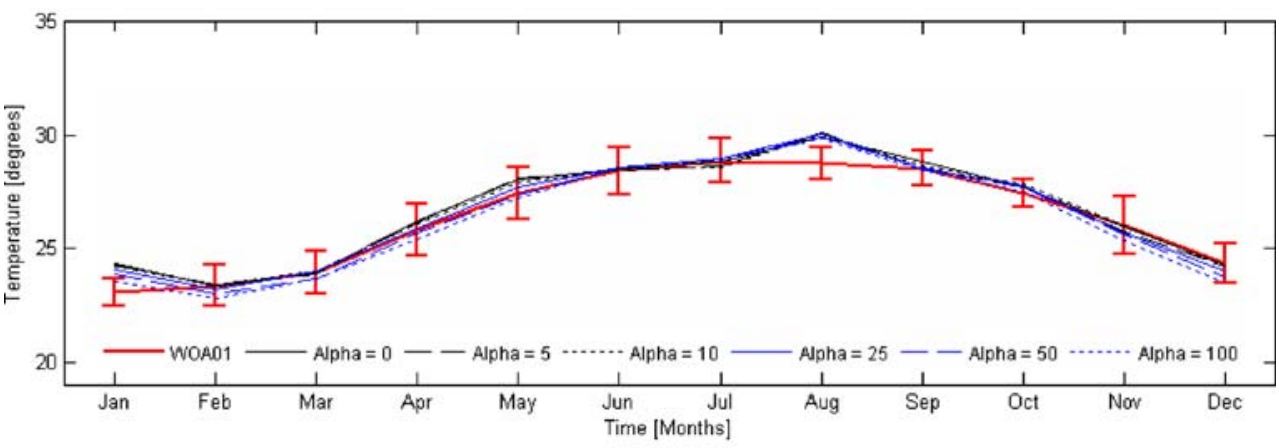

Southern $\operatorname{SCS}\left(5^{\circ} \mathrm{N}, 116^{\circ} \mathrm{E}\right)$ surface layer temperature time-series

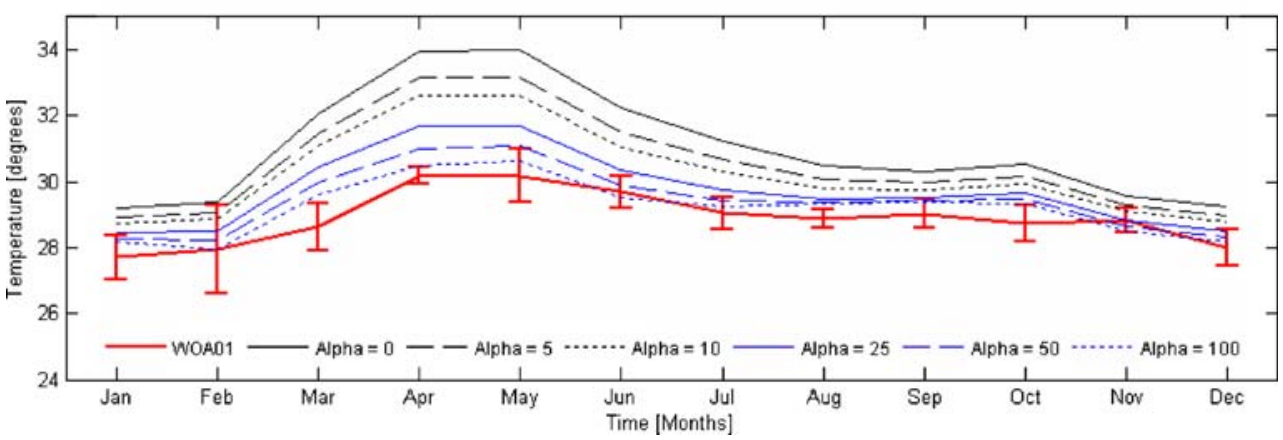

Run 5

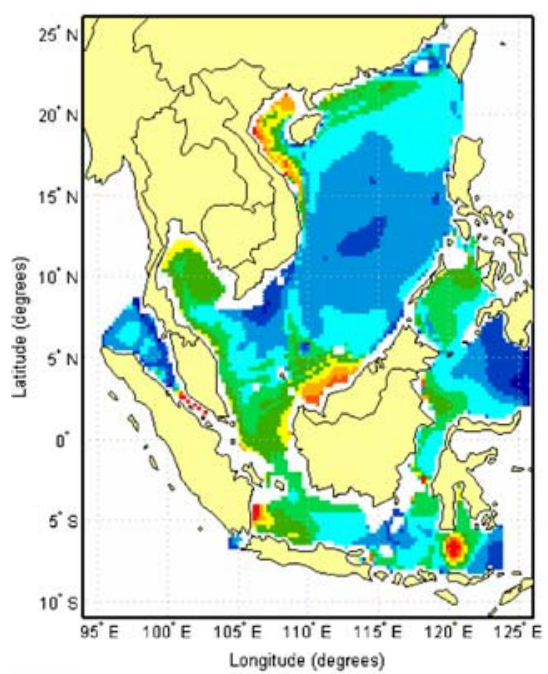

Run 7

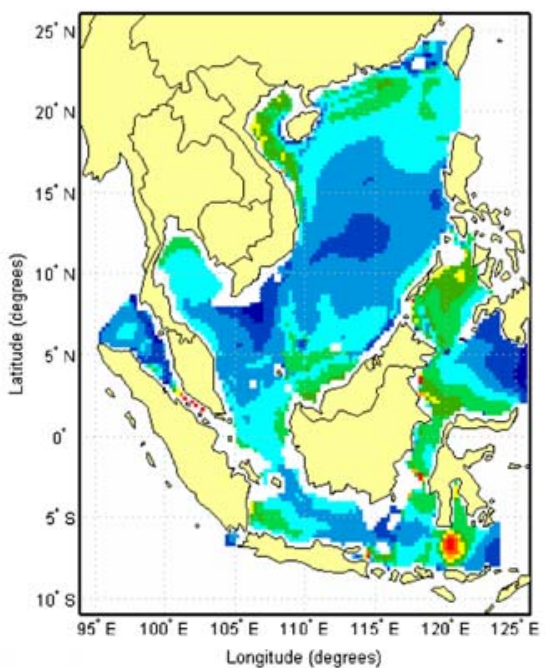

Run 8

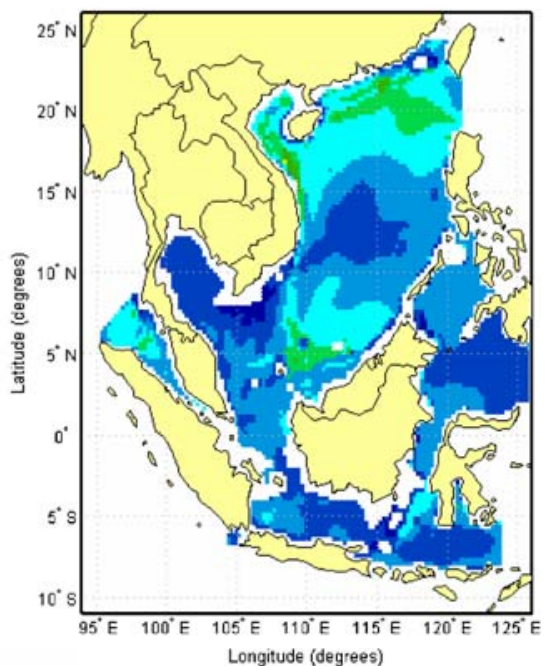

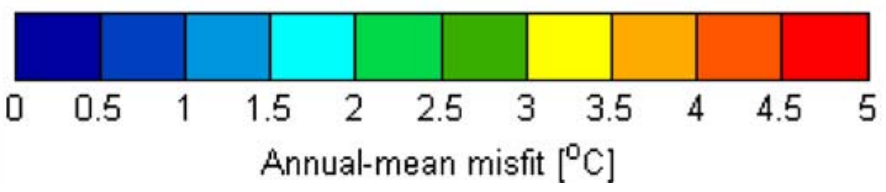

Fig. 9 Time and layer average misfit between model results with respect to World Ocean Atlas 2001 validation data (Levitus 1982; Boyer et al. 2005). See Table 2 for run definitions. SST nudging is applied 
Table 2 Definition of model runs and mean misfit with respect to World Ocean Atlas 2001 validation data (Levitus 1982; Boyer et al. 2005)

\begin{tabular}{lll}
\hline Run & Definition & GoF $\left[{ }^{\circ} \mathrm{C}\right]$ \\
\hline 5 & Run $5+$ nudging coefficient $\alpha=0$ & 1.99 \\
7 & Run $5+$ nudging coefficient $\alpha=25$ & 1.75 \\
8 & Run $5+$ nudging coefficient $\alpha=100$ & 1.58 \\
\hline
\end{tabular}

water. As this involves mixing of lower level waters, the effect of surface temperature nudging on this process is small.

\section{Model validation}

Model validation is carried out by applying the optimized model setup resulting from our sensitivity analysis in Sections 4 and 5. Two setups are assessed: one that does not and one that does apply SST nudging (Runs 5 and 8, respectively). Both setups apply monthly mean SSA and lateral transport forcing at the open model boundaries. They apply six hourly space-varying meteorological data for surface momentum and heat flux forcing. The SST nudging run applies weekly Reynolds SST data as input. For validation, modeled water levels are compared with climatological SSA data during peak NE and SW monsoon conditions (Fig. 10). Modeled surface layer temperatures are compared with climatological AVHRR SST data for similar periods (Fig. 11). Modeled profile data are compared with climatological profile data from the World Ocean Atlas 2001 (Figs. 12 and 13).

Modeled water levels are assessed in Fig. 10 by comparison with monthly mean climatological SSA data from DUACS (DUACS 2004). Model data consists of monthly mean water levels for the non-nudging model run. We assess peak NE (January) and SW (August) monsoon conditions. Based on the assumption that geostrophic flow resulting from these water levels provides us with a firstorder indication of the large-scale circulation, we will make a qualitative assessment of the circulation as resolved by our model.

In Section 2, we explained that basin-scale water levels in the SCS are characterized by "tilting" by monsoon wind stress forcing and Coriolis deflection. During the NE monsoon period, the basin-scale circulation is cyclonic, whereas during the SW monsoon, a combined cyclonic/ anticyclonic circulation will develop. The resulting currents are characterized among others by strong western-boundary currents during the NE monsoon period and by a west-toeast cross basin current. From the modeled water levels, we clearly see the effect of the monsoonal "tilting" during the $\mathrm{NE}$ monsoon period, as resembled by the higher water levels along the western model boundaries. Furthermore, we observe substantially lower water levels in the northern SCS. The resulting basin-scale circulation will be cyclonic, and strong western-boundary currents will persist along the continental shelf break. During the SW monsoon, the "tilted" water level system is less pronounced. While we do see lower values along the Vietnamese coastline and higher values near Luzon, this pattern is less distinct than the one observed from the SSA data. A striking feature for this period is the high water level to the North-West of Luzon. This feature may show a relation to the Luzon eddy, which is frequently mentioned in literature (Yang and Liu 2003). We also note that the water levels as resolved along the Vietnamese coastline will attribute to cross-basin currents from the Sunda shelf region toward the deeper SCS waters. While there are also substantial differences between the observed SSA and modeled water level, the above indicates that those features identified in Section 2 as contributing to the seasonal temperature cycle are resolved to some degree. The resulting temperature transport in which we are primarily interested will be assessed on the basis of SST data.

In Fig. 11, modeled surface layer temperatures are compared with climatological AVHRR SST data. From this figure, we observe that during the NE monsoon, the model represents the characteristic, large-scale temperature features to a reasonable degree. These features include the bifrontal temperature system in the northern SCS, which is explained in Section 2 by mixed layer entrainment by the monsoon winds, by intrusions through Luzon and Taiwan Strait and by transport of the colder water along the Chinese and Vietnamese coastlines by boundary currents. This corresponds with the modeled water levels observed from Figure 10. Discrepancies are observed over the shallow Sunda Strait $\left( \pm 2.5^{\circ} \mathrm{C}\right.$ too high $)$ and west of Hong Kong, following the China Continental Shelf $\left( \pm 3^{\circ} \mathrm{C}\right.$ too high). As concluded in Sections 4 and 5, these discrepancies are due to insufficient mixing and exchange as a consequence of neglecting the tides. Furthermore, regional processes unresolved on the scales of the model and the forcing data may play an important role at these locations. Similar conclusions are drawn with respect to upwelling of colder subsurface water against the continental shelves. Because of the coarse horizontal model resolution along the interface, this process is unresolved, explaining the misfit observed here.

During the SW monsoon, the characteristic, large-scale temperature features are resolved to a reasonable degree, with the most pronounced being the higher, uniform temperatures attributed to the increased heat flux. A notable discrepancy is observed east of Vietnam, where modeled temperatures are well below those observed from the SST data $\left( \pm 3^{\circ} \mathrm{C}\right.$ too low $)$. From the SSA data and modeled water 
Fig. 10 Monthly mean sea surface anomaly (SSA) maps (left panel) compared with monthly mean water level from model simulations (right panels) for January (top) and August (bottom) without SST nudging applied. SSA maps represent climatological conditions, assembled from 1992 to 2001 DUACS SSA data (DUACS 2005). The arrows indicate large-scale geostrophic circulation patterns. Red indicates cyclonic circulation, and black indicates anticyclonic circulation

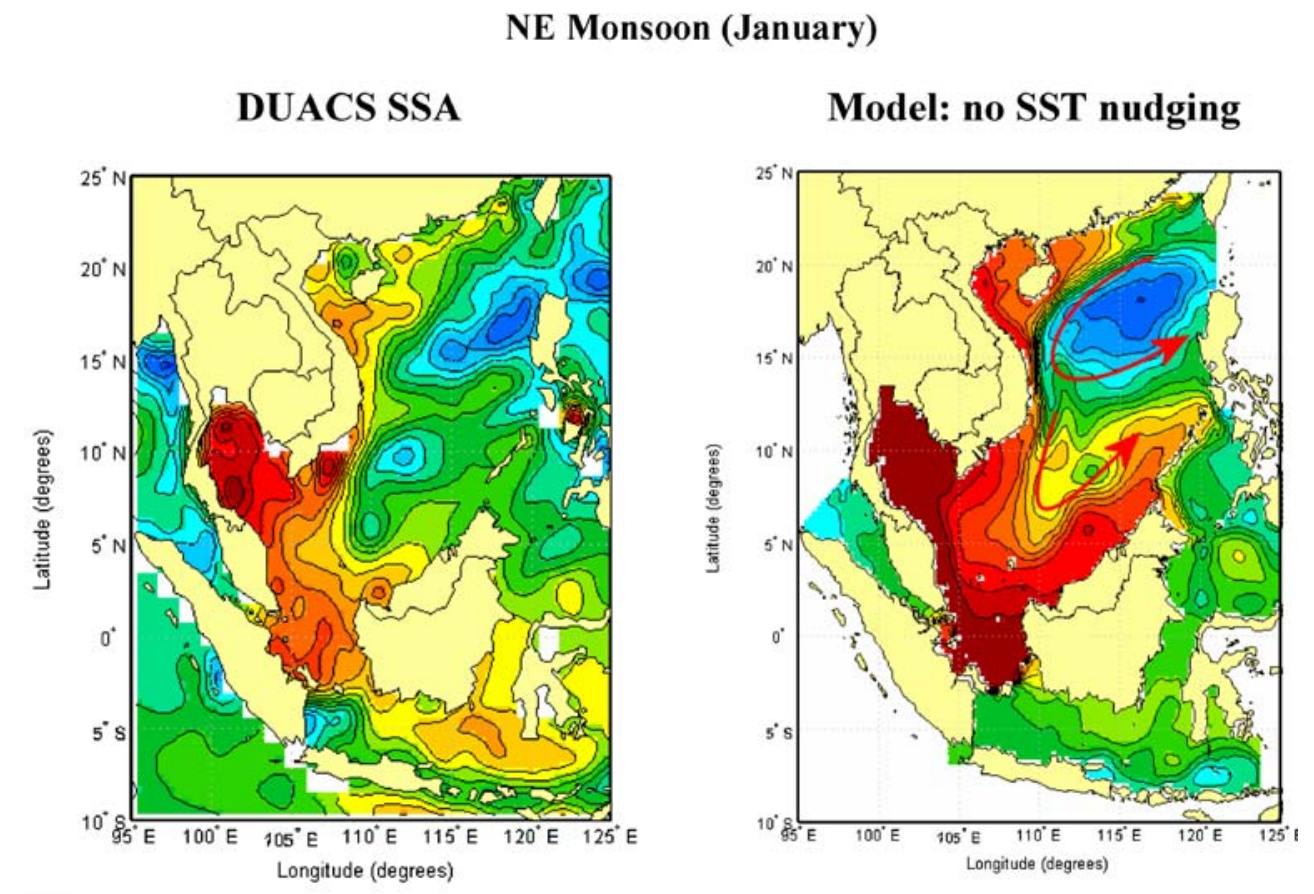

NE Monsoon (January)

SW Monsoon (August)

DUACS SSA

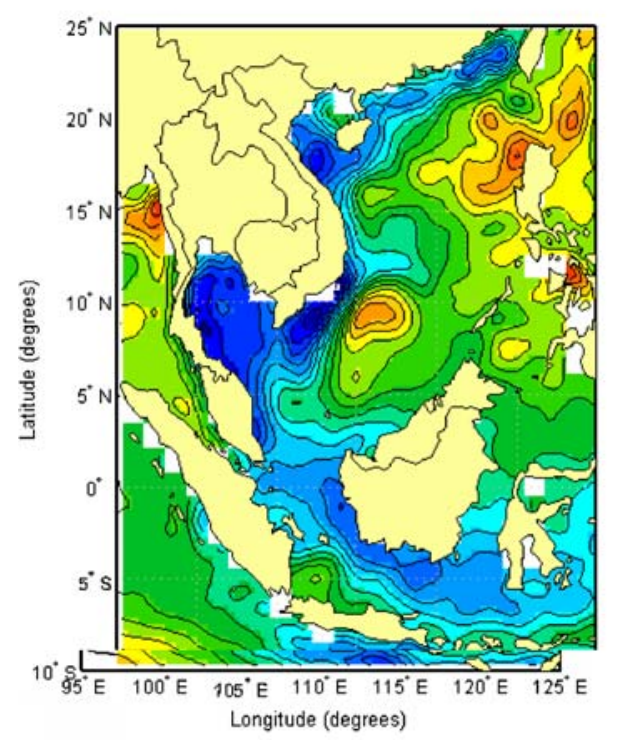

Model: no SST nudging

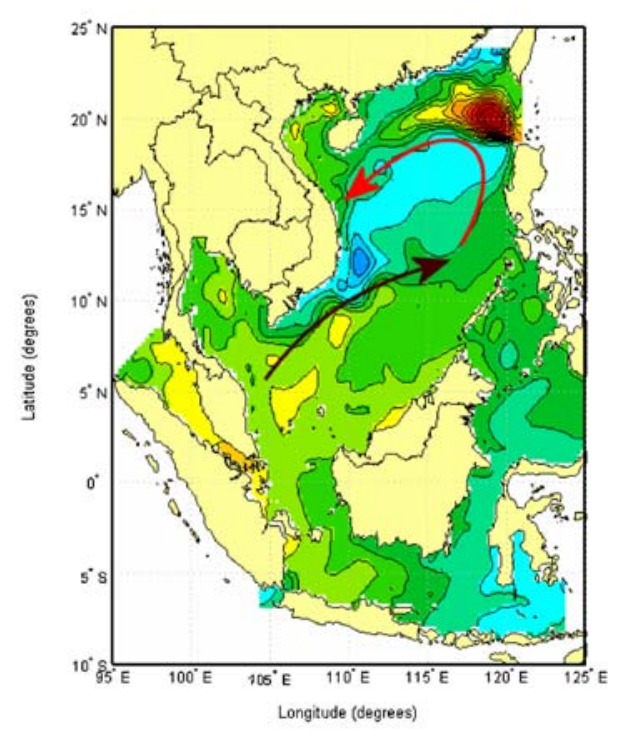

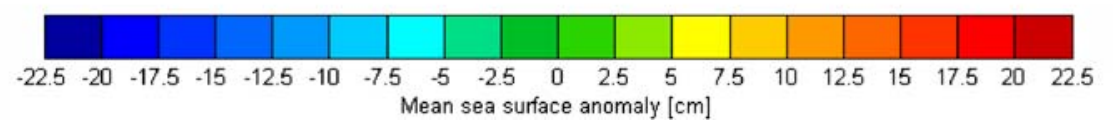

levels in Fig. 10, we observe lower water levels for this location and period. This may lead to the upwelling of subsurface water by surface divergence. The lower model temperatures may be explained by the fact that this process is not resolved by the model. On the other hand, this feature might be underestimated in the AVHRR SST data because of the long-term averaging and cloud problems. Similar to the situation of the NE monsoon, excessive temperatures are observed over the shallow Sunda Strait $\left( \pm 2.5^{\circ} \mathrm{C}\right.$ too high) during the SW monsoon.

Time series of the model and World Ocean Atlas 2001 temperature profile data for stations in the northern $\left(22^{\circ} \mathrm{N}\right.$, 
Fig. 11 Monthly mean model surface layer temperature (central and right panel), compared with monthly mean climatological sea surface temperature (SST) data (assembled from 1994 to 2004 data) from the AVHRR/ Pathfinder dataset (left panel; Vazquez 2004), representing the SST state during the NE and SW monsoon highs. Model results are shown with (right panel) and without (central panel) SST nudging applied
AVHRR / Pathfinder

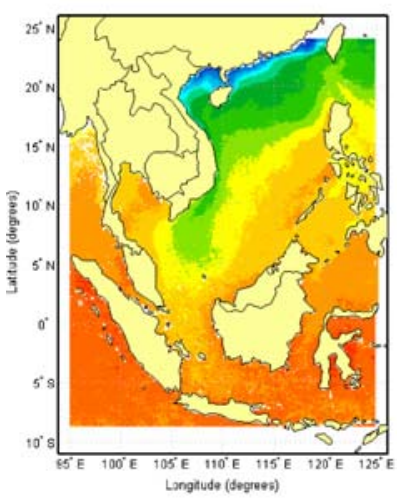

AVHRR / Pathfinder

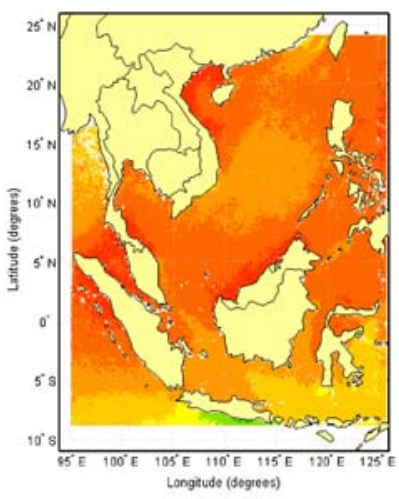

NE Monsoon (January)

Model: no SST nudging

Model: SST nudging
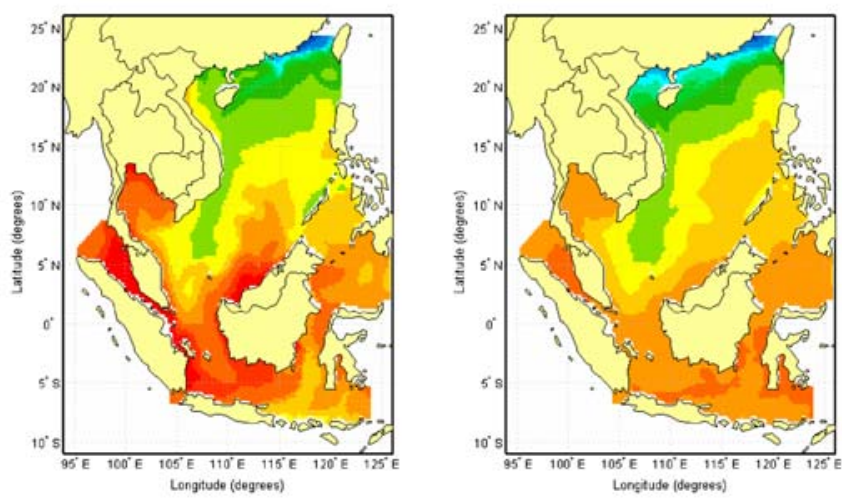

SW Monsoon (August)

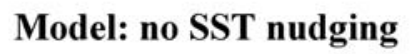

Model: SST nudging
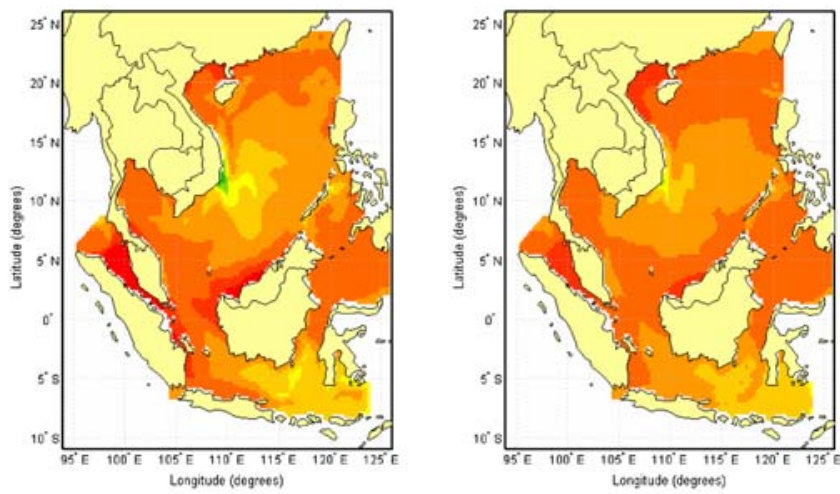

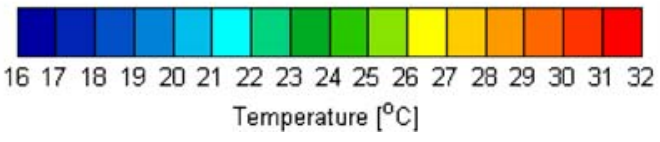

$\left.117^{\circ} \mathrm{E}\right)$ and southern $\left(5^{\circ} \mathrm{N}, 116^{\circ} \mathrm{E}\right)$ SCS are shown in Figs. 12 and 13. From these figures, we conclude that in the northern SCS, the seasonal mixed layer cycle is resolved reasonably well. The model resolves the seasonal stratification cycle, and the mixed layer temperature has the correct order of magnitude. The same holds for the mixed layer depth.

The net heat flux reaches its maximum in March, increasing from January onward (see Fig. 5). Nevertheless, the mixed layer depth does not increase during this period of the NE monsoon, which can be observed in both the model results and in the measurements. Similarly, for May to September, the SW monsoon wind speeds are increasing. The mixed layer depth does not decrease, which can be seen both in the measurements and in the model results. These two negative correlations between the mixed layer depth on the one hand and either the net heat flux or the wind forcing on the other hand are reproduced in our numerical model.

Discrepancies are observed in Fig. 13 for the southern SCS station, where model temperatures are excessively high throughout the year. The seasonal stratification cycle is resolved to a reasonable degree but with stratification occurring during the intermediate periods between the monsoons when wind speeds are lowest and the surface heat flux is highest.

It is concluded that if SST nudging is applied, the model temperature representation improves considerably in those regions where large discrepancies were observed before. This effect is not limited to surface layer temperatures. The mixed layer temperature and stratification cycles considerably improve in the shallow southern SCS and now show both the correct order of magnitude and behavior with respect to the validation data. 
Fig. 12 Time series of modeled (lower panels) and World Ocean Atlas 2001 (upper panel;

Levitus 1982; Boyer et al. 2005) temperature profiles at a model station in the deep, northern South China Sea $\left(22^{\circ} \mathrm{N}, 117^{\circ} \mathrm{E}\right)$. Model results are shown without (central panel) and with (lower panel) SST nudging applied

\section{World Ocean Atlas $2001\left(22^{\circ} \mathrm{N}, 117^{\circ} \mathrm{E}\right)$}

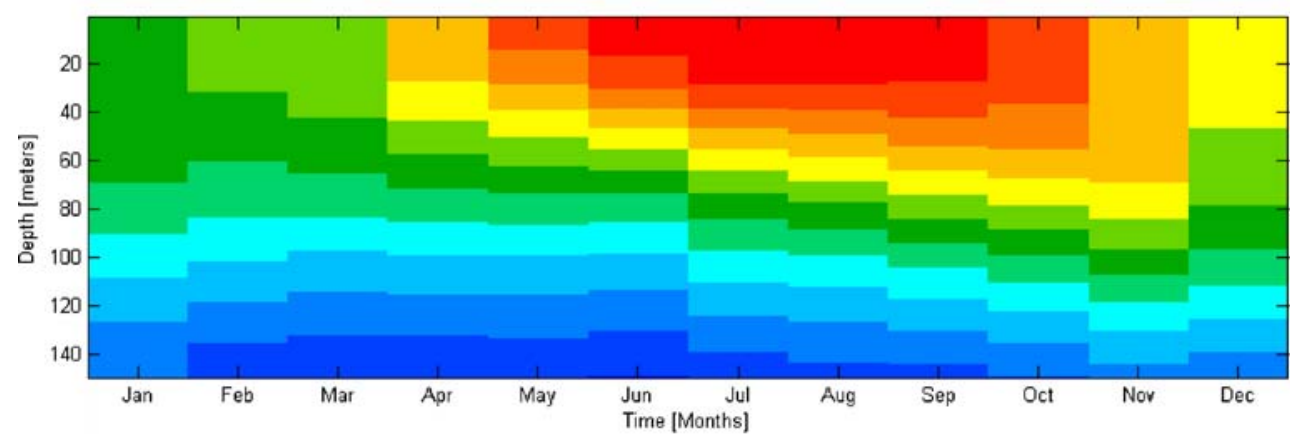

Model profile data without SST nudging $\left(22^{\circ} \mathrm{N}, 117^{\circ} \mathrm{E}\right)$

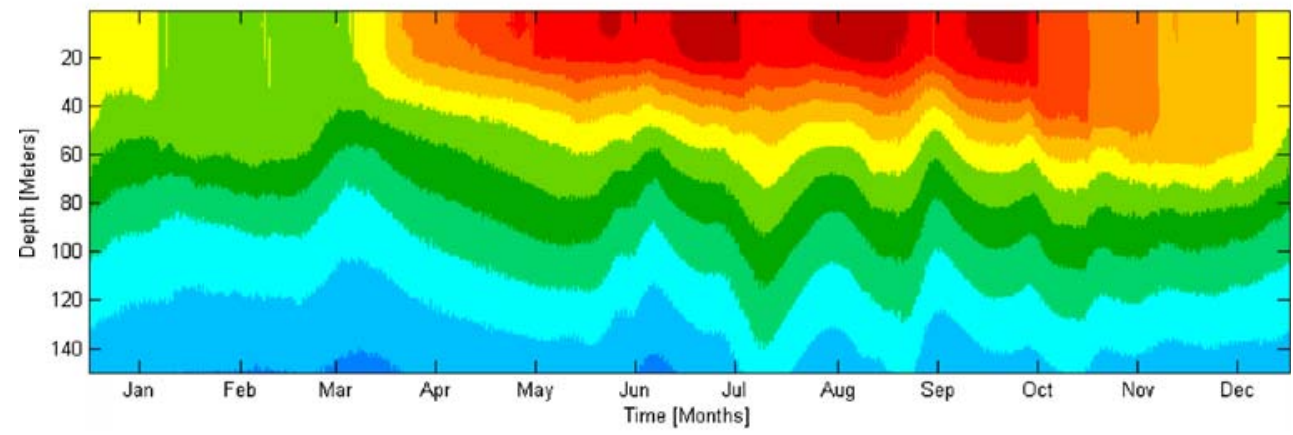

Model profile data with SST nudging $\left(22^{\circ} \mathrm{N}, 117^{\circ} \mathrm{E}\right)$
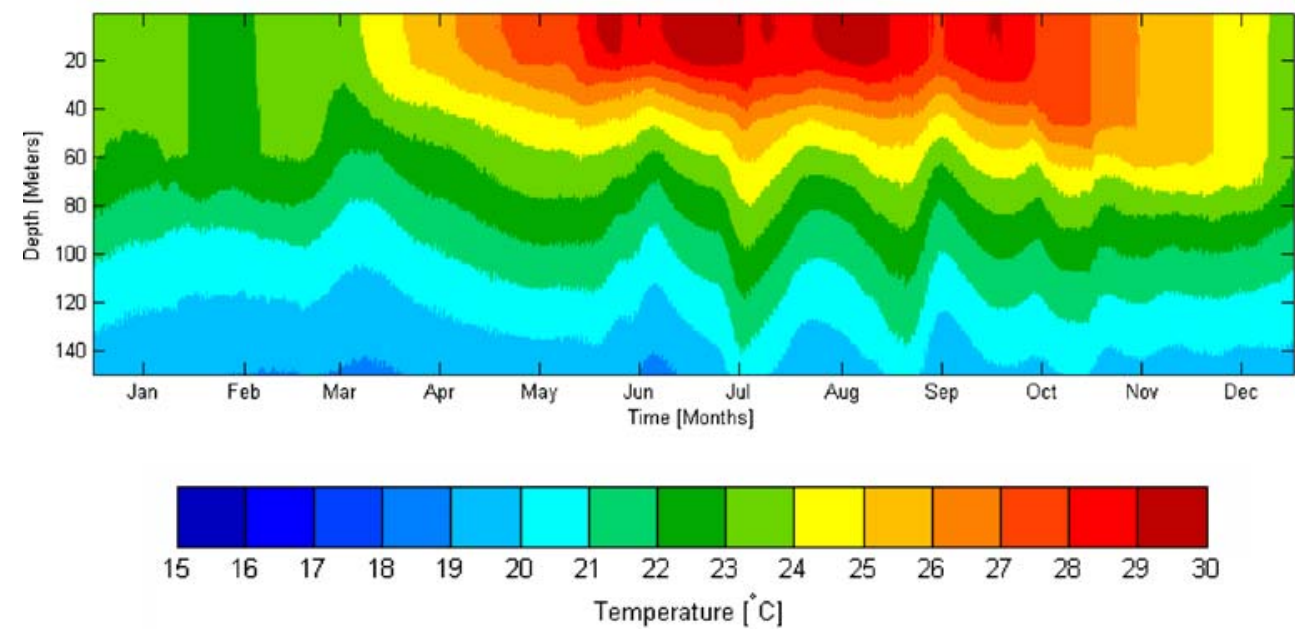

\section{Conclusions and recommendations}

The present paper describes the analysis and modeling of the large-scale SCS temperature cycle on a seasonal scale. We investigate the possibility to model this cycle in a consistent way by applying depth truncation, using monthly, time-averaged forcing and not taking into account tidal forcing. This is motivated by the associated enhanced flexibility and significant reduction in computational load, which has operational benefits for future seasonal scenario analysis and for generating transport boundary forcing for local models. The proposed model is a three-dimensional, free-surface baroclinic-reduced depth model (truncated at $300 \mathrm{~m}$ ), including salinity and temperature. To improve the models temperature representation, an optional SST nudging routine is applied. 
Fig. 13 Time series of modeled (lower panels) and World Ocean Atlas 2001 (upper panel;

Levitus 1982; Boyer et al. 2005) temperature profiles at a model station in the shallow, southern South China Sea $\left(5^{\circ} \mathrm{N}, 116^{\circ} \mathrm{E}\right)$. Model results are shown without (central panel) and with (lower panel) SST nudging applied

\section{World Ocean Atlas $2001\left(5^{\circ} \mathrm{N}, 116^{\circ} \mathrm{E}\right)$}

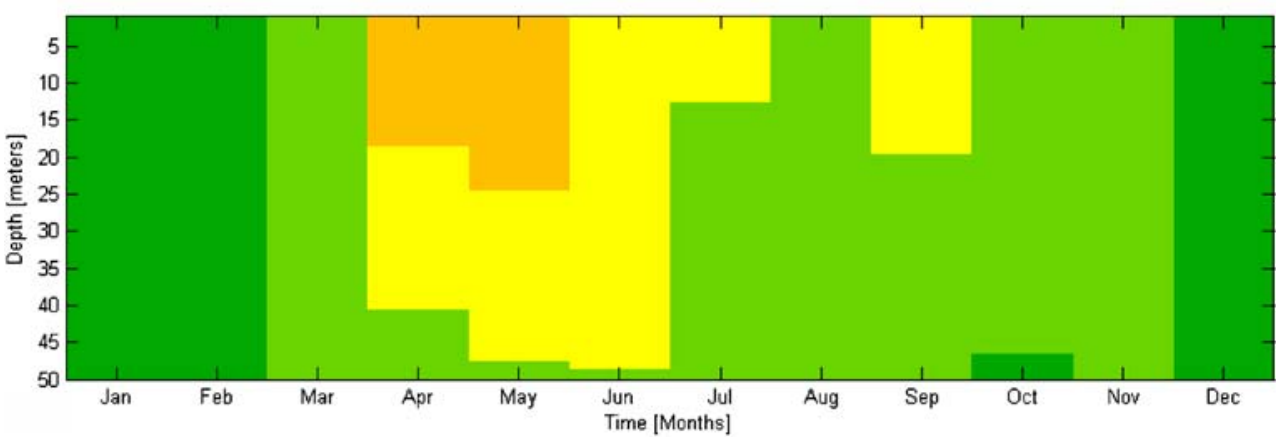

Model profile data without SST nudging $\left(5^{\circ} \mathrm{N}, 116^{\circ} \mathrm{E}\right)$

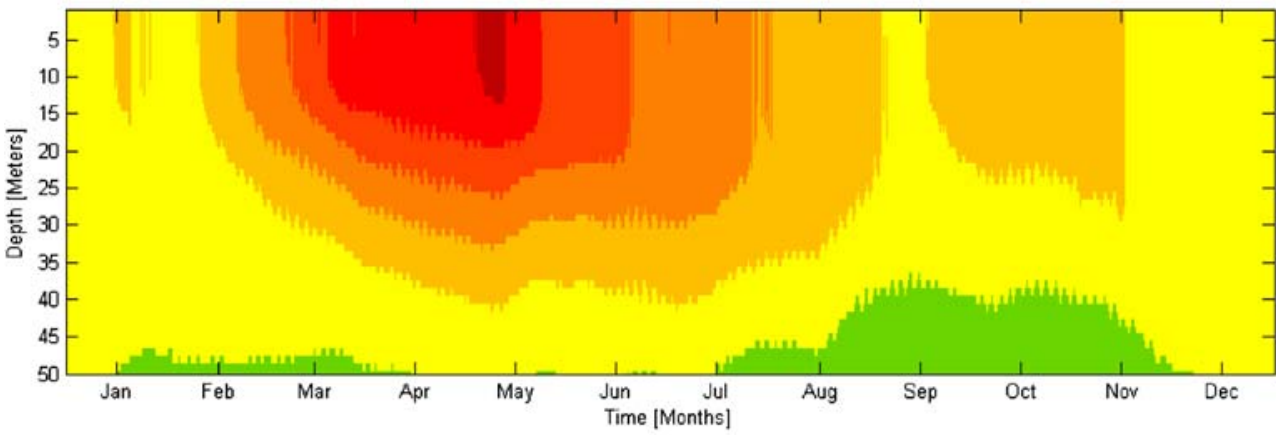

Model profile data with SST nudging $\left(5^{\circ} \mathrm{N}, 116^{\circ} \mathrm{E}\right)$

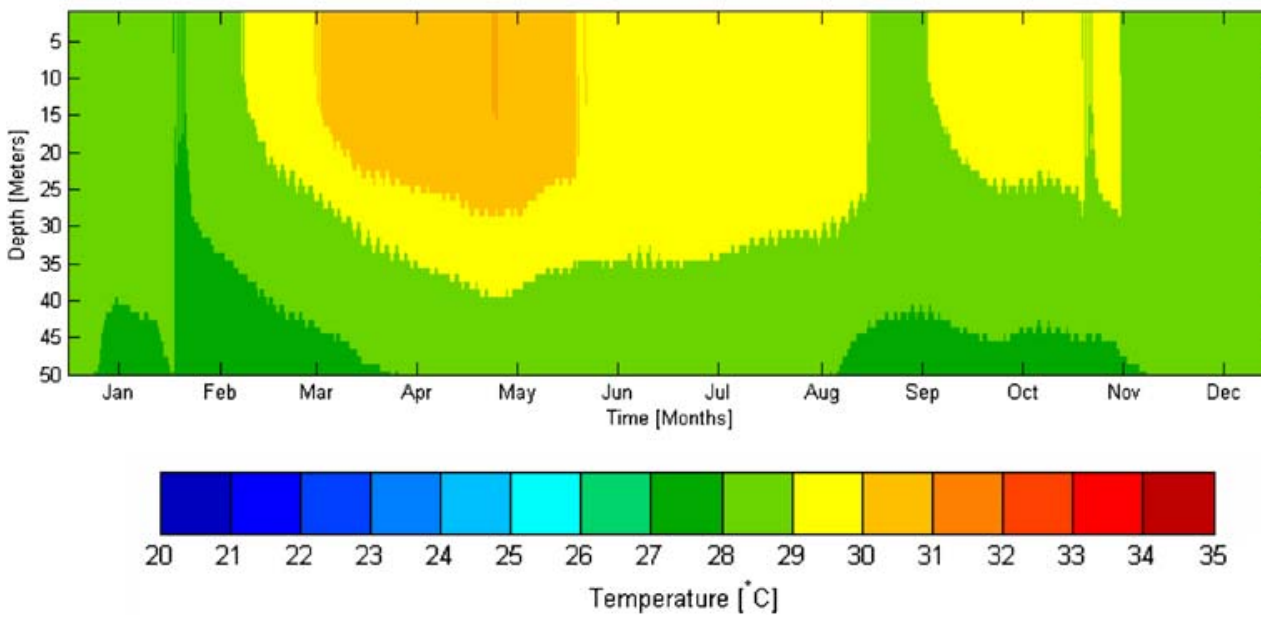

The model sensitivity analysis and validation show that in the truncated deep parts $(300 \mathrm{~m})$ of the SCS, the model resolves the seasonal temperature cycle to a reasonable degree. Model results agree to between 1.5 and $2{ }^{\circ} \mathrm{C}$ with both remotely sensed and in situ climatological temperature data. The heat flux transfer coefficients at the free surface and the resolution and quality of the free surface heat flux and momentum forcing data proved to be the most important factors in achieving a good model temperature representation. With respect to seasonal temperature variations of above $6^{\circ} \mathrm{C}$ in the northern SCS and around $4^{\circ} \mathrm{C}$ in the southern regions, this implies that the model is able to capture the seasonal temperature dynamics reasonably well. One has also to take into account the complex interplay of 
dynamic processes governing this cycle and the inaccuracy of roughly 1 to 2 degrees of the validation data. From comparison with remotely sensed SSA and SST data, it is concluded that the characteristic seasonal features are resolved, such as the seasonal residual circulation and the horizontal advective transports. Similar conclusions are drawn about seasonal stratification and mixed layer dynamics from comparison with climatological profile data.

Discrepancies are observed in the shallow regions over the China and Sunda Continental Shelves. Unresolved (tidal) mixing and exchange play an important role in the origin of these discrepancies. Clearly, the present approach works better over the deep, central SCS than over the shallow coastal zones.

Application of the SST nudging option decreases the magnitude of these discrepancies, most significantly in the shallower areas. This is not only the case for surface temperatures, but for the entire water column. This implies that the method is suitable for diagnostic applications as a robust and simple way to assimilate surface temperature data into large-scale models.

It is concluded that for the central, deep region of the SCS, the seasonal temperature cycle can be modeled in an accurate way when using a truncated depth approach and prescribing open boundary variations on longer time scales, not taking into account small-scale tidal forcing. For free surface heat flux and momentum forcing, however, data at a higher temporal resolution $(6 \mathrm{~h})$ is required to obtain good results. In the shallow regions, this approach is less suitable because of the impact of unresolved tidal mixing. If, however, observational temperature data are assimilated into the model by means of a nudging term, a reasonable model accuracy can be obtained in these regions as well. The resulting $1 / 4 \times 1 / 4^{\circ}$, 20-layer $3 \mathrm{D}$ model application, with a model time step of $2 \mathrm{~h}$ and a 1-year runtime of $3 \mathrm{~h}$, should be a practical, efficient, and flexible model for diagnostic applications at large time scales.

Because the issue of neglecting tides plays an important role in this study, it will be worthwhile to compare results for our nontidal model with those for a tide-resolving model. Such a model will be much less efficient than our nontidal model (on estimate a 1-year runtime will take approximately 3 days instead of $3 \mathrm{~h}$ ), but it will provide much insight in the effect of the tidal mixing.

We conclude that nontidal modeling at seasonal scales is a promising development for application in the SCS. There is room for further improvement and additional research. This should include increasing the models spatial resolution, most notably over the shallow shelf areas and along the shelf break (resolving upwelling). Alternatively, it might be considered to restrict the model area to the deep regions only. We note that it should be validated always that the assumption of nontidal modeling still holds.

\section{References}

Boyer T, Levitus S, Garcia H, Locarnini RA, Stephens C, Antonov JI (2005) Objective analyses of annual, seasonal, and monthly temperature and salinity for the world ocean on a $1 / 4^{\circ}$ grid. Int $\mathrm{J}$ Climatol 25(7):931-945

Centurioni LR, Niiler PP, Lee DK (2004) Observations of inflow of Philippine Sea surface water into the South China Sea through the Luzon Strait. J Phys Oceanogr 34:113-121

Chou MD, Chan PK, Michael MHY (2001) A sea surface radiation data set for climate applications in the tropical western Pacific and South China Sea. J Geophys Res 106(D7):7219-7228

Chu PC, Lu S, Chen Y (1997) Temporal and spatial variabilities of the South China Sea surface temperature anomaly. J Geophys Res 102(C9):20937-20955

Chu PC, Chen Y, Lu S (1998) Wind driven South China Sea deep basin warm-core cool-core eddies. J Oceanogr 54:347-360

Chu PC, Ma B, Chen Y (2002) The South China Sea thermohaline structure and circulation. Acta Oceanol Sin 21(2):227-261

De Goede ED, Uittenboogaard RE, Roozekrans JN, De Kok JM, Vos RJ (2000) REST3D; Remote sensing sea surface temperature for 3D North Sea modelling, Report 00-16. The Netherlands Remote Sensing Board, The Netherlands

DUACS (2004) SSALTO/DUACS User Handbook: (M)SLA and (M) ADT Near-Real Time and Delayed Time Products, Technical report CLS CLS-DOS-NT-04103, http://www.aviso.oceanobs.com/

DUACS (2005) DT CorSSH and DT SLA Product Handbook, Technical report CLS/CNESCLS-DOS-NT-05-097, http://www. aviso.oceanobs.com/

Farris A, Wimbush M (1996) Wind-induced kuroshio intrusion into the South China Sea. J Oceanogr 52:771-784

Fu LL, Cazenave A (2001) Satellite altimetry and earth sciences. Academic Press, San Diego

Gerritsen H, Schrama EJO, van den Boogaard HFP (2003) Tidal model validation of the seas of South East Asia using altimeter data and adjoint modeling. In: Proc. XXX IAHR Congress, Thessaloniki, 24-28 August 2003, Volume D, pp 239-246

Gerritsen H, Uittenboogaard, Schrama EJO (2004) Modelling of monsoon driven flows in South-East Asian waters using satellite remote sensing techniques. In: Liong SY, Phoon KK, Babovic V. Proceedings of the 6th International Conference on Hydroinformatics, Singapore, June 2004, vol 2. World Scientific, Singapore, pp 1285-1294

Hernandez F, Schaeffer P, Rio MH, Tamagnan D, Le Traon PY (2001) Mean dynamic topography for satellite altimetry: two approaches, from oceanographic data or satellite gravimetry, http://www. aviso.oceanobs.com/

Jilan S (2004) Overview of the South China Sea circulation and its influence on the coastal physical oceanography outside the Pearl River Estuary. Cont Shelf Res 24:1745-1760

Kallberg P, Simmons A, Uppala S, Fuentes M (2004) The ERA-40 Archive, Technical report series No. 17, ECMWF, http://www. ecmwf.int/

Kernkamp HWJ, Petit HAH, Gerritsen H, de Goede ED (2005) A unified formulation for the three-dimensional shallow water equations using orthogonal co-ordinates: theory and applications. Ocean Dyn 55(3-4):351-369

Lesser GR, Roelvink JA, van Kester JATM, Stelling GS (2004) Development and validation of a three-dimensional morphological model. Coast Eng 51:883-915

Levitus S (1982) Climatological atlas of the world ocean, NOAA, Professional paper No. 13, US Government Printing Office

Liu Q, Jin W, Wang X, Yang H (2001) On the annual cycle characteristics of the sea surface height in the South China Sea. Adv Atmos Sci 18(4):613-622 
Lynch JF, Ramp SR, Chiu CS, Tang TY, Yang YJ, Simmen JA (2004) Research highlights from the Asian seas international acoustics experiment in the South China Sea. IEEE J Ocean Eng 29:10671074

NGDC (2006) US Department of Commerce, National Oceanic and Atmospheric Administration, National Geophysical Data Center (2006) 2-minute Gridded Global Relief Data (ETOPO2v2), http://www.ngdc.noaa.gov/

Open University (1989) The Open University: ocean circulation. Pergamon, Oxford

Qu T (2001) Role of ocean dynamics in determining the mean seasonal cycle of the south China Sea surface temperature. J Geophys Res 106(C4):6943-6955

Qu T, Mitsudera H, Yamagata T (2000) Intrusion of North Pacific waters into the South China Sea. J Geophys Res 105(C3):64156424

Reynolds RW, Rayner NA, Smith TM, Stokes DC, Wang W (2002) An improved in-situ and satellite SST analysis for climate. J Climate 15(13):1609-1625

Rio M, Hernandez F (2003) CLS combined mean dynamic topography, http://www.aviso.oceanobs.com/

Smith SD, Banke EG (1975) Variation of the sea surface drag coefficient with wind drag. Quart J R Met Society 101:665-673
Smith SD, Fairall CW, Geernaert GL, Hasse L (1996) Air-sea fluxes: 25 years of progress. Bound Layer Meteor 78(3-4):247-290

Twigt DJ (2006) 3D temperature modeling for the South China Sea using remote sensing data, MSc. Thesis report, WL/Delft Hydraulics and Delft University of Technology

Vazquez J (2004) AVHRR ocean pathfinder-sea surface temperature data sets, http://podaac-www.jpl.nasa.gov/

Wang D, Liu Y, Qi Y Shi P (2001) Seasonal variability of thermal fronts in the Northern South China Sea from satellite data. Geophys Res Lett 28(20):3963-3966

Wang G, Li R, Yan C (2003) Advances in studying oceanic circulation from hydrographic data with application in the South China Sea. Advances in Atmospheric Research 26(6):914-920

Wang Y, Chiao L, Kamazima Lwiza KMM, Wang D (2004) Analysis of flow at the gate of Taiwan Strait. J Geophys Res 109:C02025

Wyrtki K (1961) Scientific results of marine investigations of the South China Sea and the Gulf of Thailand 1959-1961. Report, vol. 2. NAGA

Yang H, Liu Q (2003) Forced Rossby Wave in the Northern South China Sea. Deep Sea Res I 50:917-926

Yang H, Liu Q, Liu Z, Wang D, Liu X (2002) A general circulation model study of the upper ocean circulation of the South China Sea. J Geophys Res 107:C7 